\title{
Synthesis of High Molecular Weight Chitosan from Chitin by Mechanochemistry and Aging
}

Thomas Di Nardo, Caroline Hadad, Albert Nguyen Van Nhien, Audrey Moores

Submitted date: 30/01/2019 - Posted date: 30/01/2019

Licence: CC BY-NC-ND 4.0

Citation information: Nardo, Thomas Di; Hadad, Caroline; Nguyen Van Nhien, Albert; Moores, Audrey (2019): Synthesis of High Molecular Weight Chitosan from Chitin by Mechanochemistry and Aging. ChemRxiv. Preprint.

Chitosan can be obtained from the deacetylation of chitin. This process is however difficult and usually accompanied by depolymerization, affording low molecular weight chitosan. We report a novel path, relying on a combination of mechanochemitry and aging, to afford high molecular weight chitosan with minimal use of energy and solvent. This method is versatile and applicable to a number of chitin sources, including crude crustaceans and insect shells, yielding deacetylation up to $98 \%$ and remarkably high molecular weights. Chitin deacetylation was measured by magic angle spinning nuclear magnetic resonance and molecular weight by viscometry. This process affords chitosan in a safer fashion and with less materials and energy usage than the classic hydrothermal one.

File list (2)

190129-ChemRxiv-Chitin-Submission.pdf (1.30 MiB) view on ChemRxiv • download file 190121-Supplementary information paper-submission TD... (2.39 MiB) view on ChemRxiv • download file 


\title{
Synthesis of high molecular weight chitosan from chitin by mechanochemistry and aging
}

\author{
Thomas Di Nardo, ${ }^{a}$ Caroline Hadad, ${ }^{\text {bc }}$ Albert Nguyen Van Nhien, ${ }^{\mathrm{b}}$ Audrey Moores*a
}

a. Centre in Green Chemistry and Catalysis, Department of Chemistry, McGill University, 801 Sherbrooke St. West, Montreal, QC, H3A 0B8,

Canada

b. Laboratoire de Glycochimie, des Antimicrobiens et des Agroressources, UMR CNRS 7378, Université de Picardie Jules Verne, 33 rue Saint Leu UFR des Sciences, 80039 cedex Amiens, France.

c. Institut de Chimie de Picardie, FR CNRS 3085, Université de Picardie Jules Verne, 33 rue Saint Leu, 80039 Amiens Cedex, France

Keywords : Chitin, chitosan, deacetylation, high molecular weight polymer, mechanochemistry, aging, solid-state synthesis

Chitosan can be obtained from the deacetylation of chitin. This process is however difficult, because of the low solubility of chitin in most solvents, and usually accompanied by depolymerization, which limits access to high molecular weight chitosan. We report herein a novel path, relying on a combination of mechanochemitry and aging, to afford high molecular weight chitosan with minimal use of energy and solvent. We demonstrate that this method is versatile and applicable to a number of chitin sources, including crude crustaceans and insect shells, yielding deacetylation up to $98 \%$ and remarkably high molecular weights. Chitin deacetylation was measured by magic angle spinning nuclear magnetic resonance and molecular weight by viscometry. This process affords chitosan in a less dangerous fashion and with less materials and energy usage than the classic hydrothermal one.

\section{Introduction}

Biopolymers are triggering intense research interest for they are envisaged as renewable sources for materials and molecules ${ }^{1,2}$. Chitin is the second most abundant naturally produced polymer with yearly production levels in the billions of tonnes. ${ }^{3,4}$ It is a natural polysaccharide composed of $\beta$-(1-4)-linked 2- deoxy-2acetamido-D-glucose units. ${ }^{5}$ Its amide functionality constitutes an interesting manifold for functionalization and applications. ${ }^{6}$ Chitin may be deacetylated to afford chitosan, an added-value polymer with greater manipulability and solubility in water than chitin due to its free amine group. Chitosan has been developed into many functional materials from biocompatible compounds to every day commodities. Chitosan membranes feature tunable permeability to sodium chloride, glucose, tyrosine and bovine serum protein. ${ }^{7}$ Chitosan has also been investigated for protein delivery, with both bovine ${ }^{8}$ and human serum albumin. ${ }^{15}$ Successful chondrocyte growth onto chitosan scaffolds ${ }^{10}$ as well as fibroblast cell attachment and proliferation ${ }^{11}$ show promise for tissue growth. Water treatment with low concentrations of chitosan of $0.8 \mathrm{wt} \%$ or less, completely eliminated bacterial contaminations. $^{12,13}$ The use of chitosan hydrogels in drug delivery, ${ }^{14}$ chitosan encapsulated quantum dots for anti-cancer drug delivery ${ }^{15}$ and controlled drug release ${ }^{16}$ has also been investigated. Carboxymethyl chitosan has been used in cosmetics as a thickening agent due to its high viscosity and large hydrodynamic volume. ${ }^{17}$ There is a need to replace polluting, non-biodegradable plastics ${ }^{18}$ and packaging made from chitosan shows great promise due to its biodegradability and improved tensile strength when prepared by evaporation method. ${ }^{19}$ Chitosan's ability to chelate many metals, due to its amine functional group, allows it to be used as a heterogeneous catalyst support for organic transformations. ${ }^{20}$ Across its many applications, the degree of deacetylation (DDA, or the percentage of amide functions converted to amine ones) and the molecular weight of chitosan played a major role in tune tuning its properties. ${ }^{7,12,21}$ Thus the ability to precisely control these two parameters is essential.

Commercial chitin is most commonly extracted from crustaceans by undergoing a heterogeneous deproteinization process, where the crustacean exoskeleton is treated with $\mathrm{NaOH}$ from mild to harsh conditions to remove proteins in the cuticle. ${ }^{22}$ The second step to chitin extraction is a demineralization process where the exoskeleton is exposed to dilute hydrochloric acid $(\mathrm{HCl})$ at room temperature. ${ }^{23}$ Finally chitin is deacetylated to afford chitosan. All these steps are complicated by the absence of solubility of chitin in most common solvents. Chitin is only slightly soluble in highly polar solvent systems such as N,Ndimethylacetamide/lithium chloride (DMAc/LiCl). ${ }^{24}$ The most common and commercially-used chitin deacetylation method consists of a treatment in a highly concentrated $\mathrm{NaOH}$ solution $\left(\geq 50 \%\right.$ ) heated for several hours at temperatures above $100{ }^{\circ} \mathrm{C}$ and often repeated in multiple cycles to further deacetylation. ${ }^{25-}$ 28 This affords chitosan with good DDAs and medium sized molecular weights between 80 to $800 \mathrm{kDa}$. Other methods have been explored in an effort to produce a greener and safer process: maceration, ${ }^{29}$ steam explosion, ${ }^{30}$ freeze-thaw cycles, ${ }^{31}$ high temperature and pressure, ${ }^{32,33}$ sonication, ${ }^{29}$ microwaving, ${ }^{34}$ and planetary milling. ${ }^{35}$ These methods typically afford DDA in the 70 to high $90 \%$ values. Experimental details and results of these methods are detailed in Table S1. For these methods, molecular weights are not systematically reported. Yet when they are, 
molecular weight typically under $500 \mathrm{kDa}$, with the exception of the high temperature and pressure method where the chitin is mixed with a $50 \% \mathrm{NaOH}$ solution and heated to $120{ }^{\circ} \mathrm{C}$ from $3-$ 24 hours in an autoclave at 15 psi. The DDA reaches up $90.4 \%$ with $50 \% \mathrm{NaOH}$ solutions while maintaining MW of 1560 $\mathrm{kDa}{ }^{32,33}$

Mechanochemistry, the use of mechanical energy to activate chemical transformations, is currently the topic of intense research effort, ${ }^{36,37}$ in particular for biomass conversion. ${ }^{38,39}$ Chitin is no exception and the group of Yan has recently revealed that mechanochemistry was particularly effective to this end via the use of planetary milling with a large number of balls resulting in chitosan oligomers with DDA of $76.4 \%$ and MW of $6.3 \mathrm{kDa} .{ }^{35}$ They expanded this chemistry with the group of Kerton to achieve conversion of chitin into $\mathrm{N}$-acetyl-D-glucosamine monomer and dimers with 5.1 and 3.9 wt\% respectively via milling showing that harsh milling conditions can depolymerize chitin. ${ }^{40}$ Accelerated aging has also emerged as a method to access inorganic and organic materials with very low energy input. ${ }^{41-43}$ For chitin deacetylation, low temperature solution aging ${ }^{28}$ has been reported and yields highly deacetylated chitosan with $\sim 90 \%$ DDA, at the expenses of aging times close to a month. Also, although the MW was not formally measured, depolymerization levels above $70 \%$ were phenomenologically established by the excellent water solubility of the resulting samples.

In these methods, the depolymerization of chitin/chitosan by nucleophilic attack of the chitin glycosidic bonds by hydroxide ions occurs simultaneously to deacetylation. While depolymerization is a desired reaction outcome to afford lowmolecular weight chitosan, and glucosamine monomers, ${ }^{40}$ less work was done towards high MW chitosans (>1,000 kDa). Researchers have explored decreasing temperature and $\mathrm{NaOH}$ concentration, but it comes at the cost of a significant increase in time, and overall lower DDA. ${ }^{29-34}$ High temperature and pressure methods can yield highly deacetylated chitosan with high molecular weights although the process is energy intensive and potentially dangerous for scale-up. ${ }^{33}$ As biopolymers are sought after as ideal precursors for high-end functional material, there is merit in exploring avenues to preserve the polymer chain as much as possible. ${ }^{44}$ Indeed, high molecular weight (MW) polymers feature improved mechanical properties ${ }^{9,10,12}$ and glass transition temperature. ${ }^{45}$ Despite its high added value applications, chitin remains a largely underutilized biomass waste: there is thus a dire need to develop simpler methods of extractions, and methods able to afford a broader range of products are needed to implement the Shell Biorefinery theorized by Yan. ${ }^{6,46}$ Such a method should also seek to reduce energy, chemical and solvent input for improved sustainability, while being safe.

Below we present a study of chitin deacetylation in the solid state with $\mathrm{NaOH}$ with the aim to preserve the polymer chain. We have explored the use of low energy mechanochemistry, using mixer milling with only one ball, as well as aging. The role of time, quantity of $\mathrm{NaOH}$, humidity, and the effect of an amorphization pre-treatment of chitin was carefully studied. We also used a number of chitin sources, including commercial chitin, powdered shrimp shell, crab shell, lobster, black fly larvae and Bombyx eri larvae shells. Combining mechanochemistry, in absence of $\mathrm{NaOH}$, with aging in the presence of the base, resulted in high MW chitosan with excellent DDA levels (73-95\%). At these very high MW values, chitosans, even with DDA of $95 \%$ upwards, were not soluble under acidic aqueous conditions so we used a method based on viscometry with 1-ethyl-3methylimidazolium acetate $\left(\left[\mathrm{C}_{2} \mathrm{mim}\right][\mathrm{OAc}]\right)$ as a proxy for estimating $\mathrm{MW}$ values. DDA was calculated by ${ }^{13} \mathrm{C}$ magic angle spinning nuclear magnetic resonance (MAS NMR).

\section{Results and discussions}

\section{Mixer-mill based chitin deacetylation experiments}

High energy milling methods, such as the use of a planetary mill with several dozen balls, were previously reported to yield very efficient deacetylation of chitin, at the expense, however, of significantly reduced molecular weights. ${ }^{35} \mathrm{We}$ first decided to explore the use of lower energy milling mechanochemical methods, in an effort to obtain chitosan with distinct properties, namely high DDA and high MW. Milling using a Retsch MM 400 mixer mill with a $20 \mathrm{~mL}$ polytetrafluoroethylene (PTFE) jar and one $10 \mathrm{~mm} \mathrm{ZrO}_{2}$ ball was used as a soft solid-state reaction method (Scheme 1). In all methodology development experiments, commercial chitin (DDA=4\%) was used as a starting material (Table S2). Initial attempts at milling chitin with 5 equivalents of $\mathrm{NaOH}$ resulted in minor deacetylation (7\%) when the samples were milled for 30 minutes and worked up immediately with methanol to remove excess $\mathrm{NaOH}$ and sodium acetate by-product (Scheme 1). Increasing milling time, up to $90 \mathrm{~min}$, yielded no greater degree of deacetylation (Table S3). In an effort to improve deacetylation, the addition of stoichiometric amounts of liquids of $<1 \mu \mathrm{L} / \mathrm{mg},{ }^{47}$ also referred to as liquid assisted grinding ${ }^{48}$ (LAG), was attempted. This method has proved useful for instance for co-crystal formation $^{49}$ or metal organic framework synthesis. ${ }^{50}$ Dichloromethane, acetonitrile, ethyl acetate ethanol, methanol, and deionized water were tested for their effect in chitin deacetylation (Table S3).

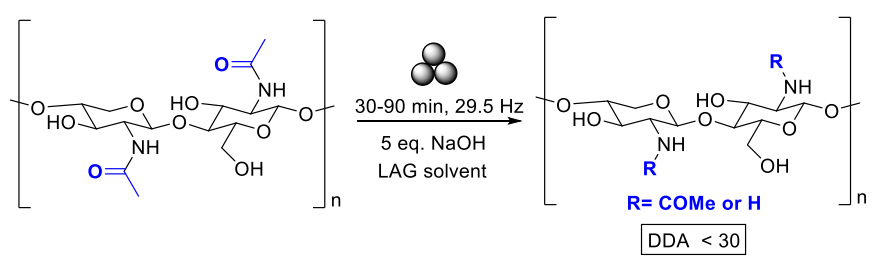

Scheme 1: Mixer-mill based chitin deacetylation experiments. DDA = $[\mathrm{H}] /([\mathrm{COMe}]+[\mathrm{H}]) \times 100, \mathrm{LAG}$, solvent $10 \mathrm{wt} \%$ : none, dichloromethane,
acetonitrile, ethyl acetate, ethanol, methanol, deionized water. Typical
experimental conditions: chitin $(105 \mathrm{mg})$, NaOH, $5 \mathrm{eq}(95 \mathrm{mg})$ based on experimental conditions: chitin ( $105 \mathrm{mg}), \mathrm{NaOH}_{\text {, }} 5$ eq. $(95 \mathrm{mg})$ based on
glucosamine unit, loaded to a PTFE jar with a $\mathrm{ZrO}_{2}$ ball.

The best result obtained with this strategy was $23 \%$ DDA while using the $20 \%$ deionized water LAG 1:5 chitin: $\mathrm{NaOH}$ mixture (Table S3). In practice, chitin is considered to have been converted to chitosan once its DDA reaches 50\%, yet, for application, chitosan featuring DDA greater than $70 \%$ is preferred for their improved solubility in dilute acid. ${ }^{8,10-}$ 17,19,20,51-53 This first attempt at soft mechanochemistry and LAG 
was not conclusive, and we reasoned that the lack of amorphization could be problematic in favoring the reaction.

\section{Mechanochemical amorphization of chitin as a pre- treatment to deacetylation}

It is well-known that crystallinity in biopolymer restricts their reactivity. For instance, the acid hydrolysis of cellulose occurs more readily onto amorphous regions. ${ }^{54}$ Commercial chitin itself is highly crystalline, ${ }^{55}$ which has been shown to slow or even prevent significant deacetylation, including in liquid-phase enzymatic protocoles. ${ }^{56}$ Chitin can benefit from amorphization to improve access to acetyl sites ${ }^{31,55}$ through increased internal permeability. ${ }^{57} \mathrm{We}$ thus looked into the effect of dry milling pure chitin, in absence of any reagent, by probing the crystallinity index (CrI) of the product by X-ray diffraction (XRD). We first mixer-milled commercial chitin in PTFE using one $\mathrm{ZrO}_{2}$ ball for 30 mins. This afforded very limited amorphization, yielding a crystallinity index $(\mathrm{CrI})$ of $52.4 \%$ as compared to $65.8 \%$ for untreated practical grade (PG) chitin (Figure 1). Further milling in PTFE with a zirconia ball for 90 min yielded limited improvement with a $\mathrm{CrI}$ of $48.8 \%$. In order to improve impact, ${ }^{58}$ harder materials, i.e. steel and $\mathrm{ZrO}_{2}$ jars equipped with one ball of the same material, were tested. In $30 \mathrm{~min}$, significant amorphization had taken place with a crystallinity index of $14.3 \%$ for PG chitin milled in stainless steel, $19.7 \%$ for PG chitin mill in $\mathrm{ZrO}_{2}$. Vickers hardness and density $(\rho)$ can be commonly found in material technical data sheets. For PTFE (5-60 MPa, $\left.\rho=2.2 \mathrm{~g} / \mathrm{cm}^{3}\right), \mathrm{ZrO}_{2}\left(10-14 \mathrm{GPa}, \rho=5.68 \mathrm{~g} / \mathrm{cm}^{3}\right)$ and stainless steel $\left(1-2 \mathrm{GPa}, \rho=7.7 \mathrm{~g} / \mathrm{cm}^{3}\right)$. Both the inverse of the Vickers hardness and the density were correlated to the amorphization measures as $\mathrm{CrI}$ (Figure 2). Indeed denser materials $\left(\mathrm{ZrO}_{2}\right.$ and steel) are better able to disrupt chitin, a material with high Vickers hardness (245-784 MPa) itself and fairly low density $\rho=1.3 \mathrm{~g} / \mathrm{cm}^{3}{ }^{59}$ Amorphization can also be correlated with FTIR, comparing commercial chitin and the zirconia amorphized chitin. The amorphized chitin IR shows loss of peak at $\sim 3450$ $\mathrm{cm}^{-1}(\mathrm{OH})$, merging of the amide peaks at $1663 \mathrm{~cm}^{-1}$ and 1612 $\mathrm{cm}^{-1}$ as well as loss of the out of plane $\mathrm{N}-\mathrm{H}$ at $745 \mathrm{~cm}^{-1}$ and 690 $\mathrm{cm}^{-1}\left(\right.$ Figure S1) ${ }^{60,61}$

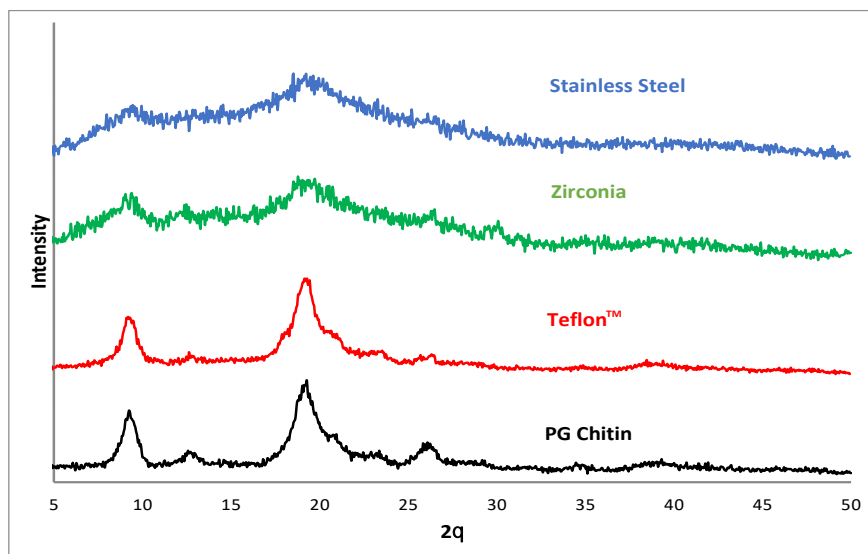

Figure 1 : XRD spectra of chitin and chitin milled in PTFE (90 min), Stainless steel (30 min) or $\mathrm{ZrO}_{2}(30 \mathrm{~min})$ jars.
While good amorphization was achieved in hard material jars, the impact on chitin MW is another important parameter to control. The intrinsic viscosity $[\eta]$ of a polymer in solution is classically used to determine its $\mathrm{MW} .{ }^{62-65} \mathrm{DMAc} / \mathrm{LiCl}$ is a classic solvent system used in the literature for MW determination of chitin, yet it did not allow complete dissolution of our chitin samples, suggesting that any measure would underestimate MW. ${ }^{51}$ Additionally $\mathrm{DMAc} / \mathrm{LiCl}$ is known to be corrosive, resulting in possible degradation of the polymer during the dissolution process. ${ }^{51}$ Chitin in the range of 5,000 $\mathrm{kDa}^{65}$ have been reported previously using these suboptimal systems. $\left[\mathrm{C}_{2} \mathrm{mim}\right][\mathrm{OAc}]$ however has been shown to be a much better solvent for both chitin and chitosan. ${ }^{66-68}$ We successfully dissolved PG chitin completely, and found a [ $\eta]$ of 7.23. Classically, polymer samples of known MW, typically determined by gel permeation chromatography (GPC), are used as reference to build a calibration curve correlating the intrinsic viscosity to MW. The Mark-Houwink parameters, $\alpha$ and K, are hence obtained from Equation 1.

$$
[\eta]=K \cdot M W^{\alpha}
$$

Equation 1 - Mark-Houwink equation to calculate Mv from intrinsic viscosity, where $\eta$ is the intrinsic viscosity of the polymer solution and $\alpha$ and $K$ are the MarkHouwink parameters

At low MW regime, chitin samples of known MW could be easily obtained by acetylating reference chitosans. At high MW regime ( $>1,500 \mathrm{kDa}$ ), we no longer had access to either chitin or chitosan samples for which the MW had been determined unequivocally. By using low MW regime calibration, we could obtain $\alpha$ and $\mathrm{K}$ values, which we used to estimate PG chitin MW to be $27,100 \mathrm{kDa}$. This value is much larger than what is usually reported, and the overestimation is likely caused by a change in viscosity behaviour between low and high MW regimes.

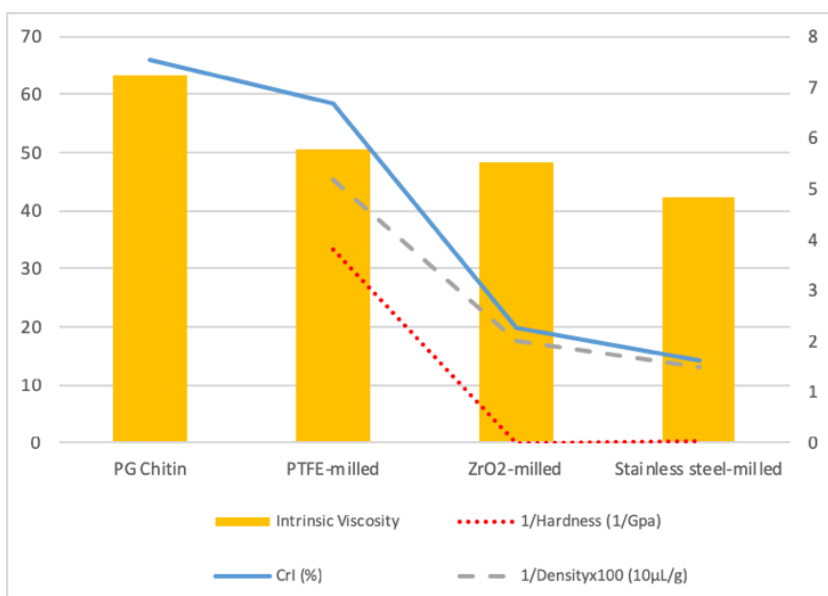

Figure 2 - Comparison chart of the [ $\eta$ ] (yellow bars - right ordinate) and CrI (blue line left ordinate) for as-is and amorphized chitin samples with the [1/Vickers hardness] (dotted red line - left ordinate) and the [1/densityx100] (dashed gray line - left ordinate) of the apparatus material. Amorphization conditions: RT for $30 \mathrm{~min}$ in PTFE, $\mathrm{ZrO}_{2}$ and stainless steel apparatus respectively.

With soft milling conditions (one ball, vibrational mill), we explored if we could maintain high viscosity - hence high MW while amorphizing the material for further treatment. When milled for 30 min in PTFE, $\mathrm{ZrO}_{2}$, and stainless steel, the [ $\left.\eta\right]$ were 
5.80, 5.52 and 4.86 respectively (Figure 2). This method of milling with one ball thus afforded limited decrease in $[\eta]$. For reference, the Yan group used $100 \mathrm{ZrO}_{2}$ balls of $0.5 \mathrm{~mm}$ for 80 min to afford chitin of MW of $79.7 \mathrm{kDa}^{35}$, which would correspond to $[\eta]$ of 1.65. This exemplifies how careful selection of mechanochemical conditions may lead to vastly different results. In the following work, we used a $\mathrm{ZrO}_{2}$ jar and one $\mathrm{ZrO}_{2}$ ball for the amorphization step, as they provide an excellent compromise of high $[\eta]$ with good loss of crystallinity (19.7\% of CrI).

\section{Chitin deacetylation by amorphization followed by aging studies}

The amorphization treatment described above is still fairly intensive and we sought to use as mild as possible deacetylation conditions. We thus explored the use of aging, in dry and humid environments since it has been hypothesized that water plays a large role in depolymerization by activating the glycosidic bond for nucleophilic attack in a basic environment ${ }^{69}$ Humidity levels in the samples during aging were monitored thanks to controlled humidity chambers. Salt saturated aqueous solution prepared with $\mathrm{K}_{2} \mathrm{CO}_{3}, \mathrm{NaCl}$, and $\mathrm{K}_{2} \mathrm{SO}_{4}$ were able to afford stable 43,75 , and $98 \%$ relative humidity (RH) environments inside a sealed enclosure, respectively. ${ }^{41}$ Pure chitin samples were first amorphized by mixer milling in $\mathrm{ZrO}_{2}$ apparatus for $30 \mathrm{~min}$, before being mixed with $\mathrm{NaOH}$ and milled five minutes further in a PTFE jar with $\mathrm{ZrO}_{2}$ ball to ensure homogeneous mixing. The sample was then aged in the various RH environment for 6 days at room temperature. Complete results of this studies are shown in Table S4. Interestingly $\mathrm{RH}$ of $98 \%$ afforded a DDA of $73 \%$ (Scheme 2). For this highly deacetylation sample, IR and ${ }^{13} \mathrm{C}$ MAS NMR spectra are provided as Figure S2 and S3. To measure MW, GPC is commonly used for chitosan using an acetic acid buffer. One of the difficulties encountered in this project is that despite having high DDAs the solubility of the aged chitosan was low.
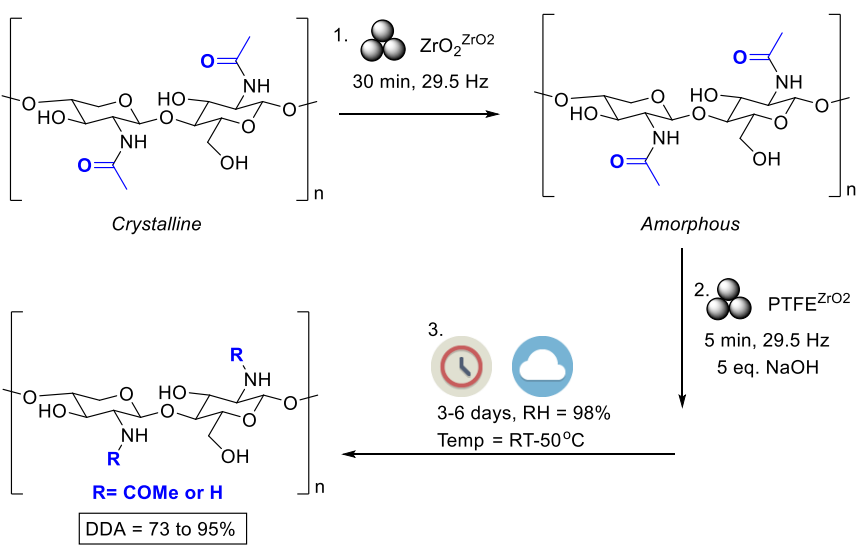

Scheme 2: Amorphization/aging based chitin deacetylation experiments. DDA = $[\mathrm{H}] /([\mathrm{COMe}]+[\mathrm{H}]) \times 100$. Typical experimental conditions: chitin $(200 \mathrm{mg})$ mg) based on glucosamine unit, loaded to a PTFE jar with a $\mathrm{ZrO} 2$ ball, followed by aging at $98 \%$ RH for 6 days.
The material recovered from the reaction described in scheme 2 was left to dissolve in an acetic acid buffer $(0.3 \mathrm{M}$ acetic acid, $0.25 \mathrm{M}$ sodium acetate, $0.8 \mathrm{mM}$ sodium azide), following literature dissolution methods, ${ }^{70}$ and then filtered using a 0.45 $\mu \mathrm{m}$ PTFE filter. Less than $5 \%$ in weight was dissolved by this method, indicating that most the sample featured MW of high values. The soluble fraction was inspected with GPC, yielding MW of 4-20 kDa. This could be indicative of residual depolymerization. We thus turned again to viscometry to determine the MW of chitosan samples. Attempts at dissolution in buffers of $1 \%$ acetic acid, $2 \%$ acetic acid, $0.8 \%$ lactic acid and $5 \% \mathrm{DMAc} / \mathrm{LiCl}$ solutions also proved fruitless as can be seen in photos Figure S4. This is evidence that we made chitosan with higher MW than commercial ones. For reference, the highest molecular weight reported in the literature for chitosan samples was $1,560 \mathrm{kDa}$ and these samples are soluble in acidic conditions. ${ }^{33}$ This feature is particularly interesting since nonwater soluble chitosans can be used towards application where water solubility is problematic such as metal polluted water remediation, or food packaging. Luckily, our samples were soluble in $\left[\mathrm{C}_{2} \mathrm{mim}\right][\mathrm{OAc}]$ (Figure $\mathrm{S} 4$ ), so viscometry measurements were made with this solvent. Like with chitin,

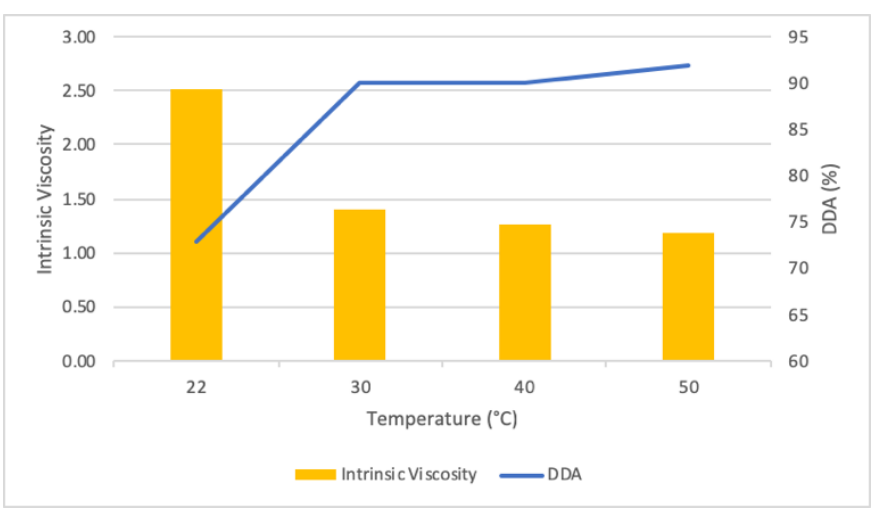

Mark-Houwink parameters could be determined for the low MW regime, but not for the high one. Samples treated according to the method described in scheme 2 at RT afforded an $[\eta]$ of 2.52, corresponding to a MW of 4,040 kDa as calculated by the MarkHouwink of the low MW regime. In order to further boost DDA while maintaining MW, optimization of reaction conditions was explored by modifying aging temperature, aging time, and $\mathrm{NaOH}$ equivalents (Table $\mathrm{S} 5$ and $\mathrm{S6}$ ).

Figure 3: Effect of the temperature during the aging step in the amorphization/aging based chitin deacetylation experiments on Intrinsic Viscosity [ $\eta]$ and DDA Conditions of scheme 2 .

\section{Chitin deacetylation: reaction optimization}

We first investigated the effect of the temperature during aging under RH of $98 \%$ for 6 days (Figure 3, Scheme 2). To modulate this parameter, the humidity chambers were placed in an oven. Raising aging temperatures was expected to accelerate all hydroxy-catalyzed reactions, deacetylation, but also depolymerization. From RT $\left(22^{\circ} \mathrm{C}\right)$ to $30^{\circ} \mathrm{C}$, DDA raised to $90 \%$, while the $[\eta]$ was strongly affected and dropped from 2.52 to 1.41. Raising the temperature further up to $50{ }^{\circ} \mathrm{C}$, marginally improved the DDA up to $92 \%$ and further eroded the [ $\eta]$ down 
to 1.18 . Then we studied more the kinetics of the reaction by looking into aging times of 3, 4, 5 and 6 days, at RT, keeping all other conditions described in scheme 2. Under these conditions, fairly stable $[\eta]$ ranging from 2.52 to 2.76 were observed (Figure 4 , orange solid columns). A sharp increase of DDA from $53 \%$ at 3 days to $76 \%$ at 4 days was observed, followed by a plateau thereafter (Figure 4, brown solid line). At $50^{\circ} \mathrm{C}$, DDAs were ranging between $90 \%$ and $95 \%$ from 3 to 6 days, revealing a much faster kinetic than at RT (Figure 4, green dashed line)). The $[\eta]$ was affected too, with values slowly decreasing from 1.27 to 1.18 from 3 to 6 days of aging.

The best $[\eta]$ value obtained for chitosan with good DDA, under these conditions, is 2.52 . This is 1 [ $\eta]$ unit higher than the largest commercial chitosan (MW=800 kDa). This method is also versatile since varying the reaction time and temperature afforded chitosans of a varied range of DDA and [ $\eta$, including ones comparable to commercial chitosans.

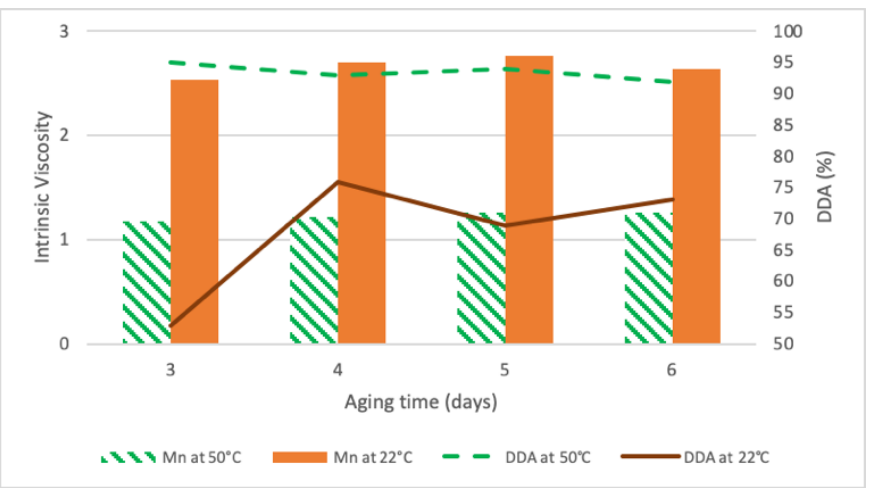

Figure 4: Reaction kinetics for the amorphization/aging based chitin deacetylation experiments. [ $\eta$ ] and DDA for reactions performed at 22 and $50^{\circ} \mathrm{C}$. Conditions of experiments. $[\eta]$ and DDA for reactions pert
scheme 2 additionally varying aging time.

We then explored the role of amorphization pretreatment in these aging experiments, at aging temperatures of 22 and $50^{\circ} \mathrm{C}$, in 6 days (Figure 5). At room temperature, skipping the amorphization pre-treatment provided poor DDA of 59\%, compared to $73 \%$ with amorphization. Conversely, no amorphization allowed to preserve a really high $[\eta]$ of 3.19 , compared to 2.52 with the extra step. At $50^{\circ} \mathrm{C}$ interesting results are observed. No amorphization secured excellent [ $\eta]$ of 3.01 and excellent DDA of $87 \%$. This demonstrated that while amorphization is a good method for accelerating deacetylation, it is by no means a sine qua none condition to excellent DDAs. As absence of amorphization secured exceptionally high $[\eta]$ of 3.12 (Table S5, 3 days at $50^{\circ} \mathrm{C}$ ), a value well above measured commercial chitosan sources, [ $\eta]$ of 1.62. Finally, we were interested in limiting the chemical input in this reaction, while maintaining amorphization and explored the decrease of the amount of added $\mathrm{NaOH}$. At $98 \% \mathrm{RH}$ and $50^{\circ} \mathrm{C}$ aging, $1: 5$ chitin: $\mathrm{NaOH}$ afforded 95\% DDA, while 1:4, 1:3, 1:2, 1:1, yielded 86, 68, 52, and 30\% DDA respectively (Figure S5, Table S6). Reaching a DDA of $86 \%$ with $1: 4$ chitin: $\mathrm{NaOH}$ is an improvement in $\mathrm{NaOH}$ equivalents over recent milling deacetylation methodologies, ${ }^{35,71}$ where $1: 5$ chitin: $\mathrm{NaOH}$ mixture was used and a significant decrease compared to conventional methods ${ }^{26}$ with 1:40 chitin: $\mathrm{NaOH}$ (Table S1). At $1: 4$ ratio, the $[\eta]$ is also improved to 1.84 from 1.81 from $1: 5$ ratio.

\section{Scale-up of chitin deacetylation by aging}

To test scale-up feasibility of the process, $10 \mathrm{~g}$ of chitin was used in the simplified approach consisting of mixing commercial crystalline chitin with $\mathrm{NaOH}$ (1:5 molar ratio) and milled in a planetary mill for 5 mins, followed by aging for 3 and 6 days in $98 \% \mathrm{RH}$ at $50^{\circ} \mathrm{C}$ was used. Either Stainless steel or $\mathrm{ZrO}_{2}$ jars were used as indicated, each with 5 balls $(10 \mathrm{~mm})$ of the same material. The successful scale-up yielded chitosan up to $89 \%$ DDA and $[\eta]$ of 2.47 , where longer aging times yielded higher DDA and lower [ $\eta]$. Milling media also had an effect, where the higher density stainless steel improved DDA \% but also decreased $[\eta]$ (table 2).

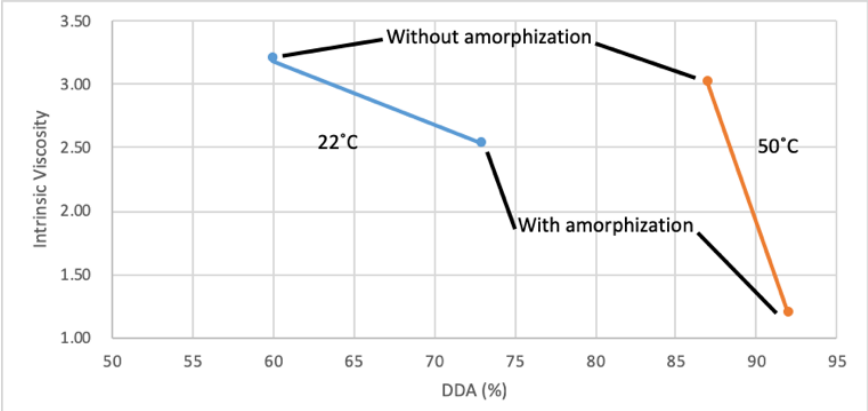

Figure 5: $[\eta]$ vs DDA graph for the aging based chitin deacetylation experiments, with or without amorphization pre-treatment, at 22 or $50^{\circ} \mathrm{C}$. The reactions were performed of 6 days, at chitin: $\mathrm{NaOH}$ ratios of 1:5, with amorphization in $\mathrm{ZrO}$

Table 2: DDA and $[\eta]$ results on $10 \mathrm{~g}$ scaled-up deacetylation of commercial chitin consisting of 5 min milling in a planetary mill, followed by aging at $50^{\circ} \mathrm{C}$ at $98 \% \mathrm{RH}$

\begin{tabular}{|c|c|c|c|}
\hline Aging Time (days) & Milling apparatus & $\%$ DDA & $\begin{array}{c}\text { Intrinsic } \\
\text { Viscosity }\end{array}$ \\
\hline \multirow{2}{*}{3} & $\mathrm{ZrO}_{2}$ & 75 & 2.47 \\
\cline { 2 - 4 } & stainless steel & 85 & 2.31 \\
\hline \multirow{2}{*}{6} & $\mathrm{ZrO}_{2}$ & 83 & 2.35 \\
\cline { 2 - 4 } & stainless steel & 89 & 2.28 \\
\hline
\end{tabular}

\section{Scope: other chitin sources}

Besides commercial chitin, we were interested to study the synthetic method developed herein directly on untreated crustacean and arthropod shells. We thus tested shrimp, lobster, crab, fly larva larvae and Bombyx eri larvae (BEL) shell, which are all composed of chitin, as well as proteins and $\mathrm{CaCO}_{3}{ }^{72}$ All biomass samples were dried, ground and sieved to particles $<125$ $\mu \mathrm{m}$, then amorphized for 30 mins in a $\mathrm{ZrO}_{2}$ jar with a $\mathrm{ZrO}_{2}$ ball. We also explored BEL samples treated with ionic liquids in order to swell the chitin for better access and remove some from proteins and $\mathrm{CaCO}_{3}$, according to a method we (Hadad, Nguyen Van Nhien) previously reported. ${ }^{73}$ All these samples were mixed with $\mathrm{NaOH}$, milled for 5 min in a PTFE jar with $\mathrm{ZrO}_{2}$ ball, and aged for 6 days at $98 \% \mathrm{RH}$ and $50{ }^{\circ} \mathrm{C}$. For these tests, we used a 
biomass: $\mathrm{NaOH}$ ratio of 1:5, which means that the chitin: $\mathrm{NaOH}$ ratio is higher, because of the presence of proteins and $\mathrm{CaCO}_{3}$. Shrimp shell reached a DDA of $95 \%$, while lobster, crab and fly larva reached $96 \%, 98 \%$ and $90 \%$ respectively (Table 3). The presence of protein and $\mathrm{CaCO}_{3}$ within untreated biomass samples meant the true $\mathrm{NaOH}$ to chitin ratio was higher than 5:1 which can explain the higher deacetylation results as compared to our model reaction. Chitin samples extracted from fly larva reached their highest DDA of $78 \%$ (Table 3), when the biomass was pretreated with $\left[\mathrm{C}_{2} \mathrm{mim}\right][\mathrm{OAc}]$. This lower DDA was rationalized by a higher crystallinity of the extracted BEL chitin. All these direct-from-biomass chitosan samples proved to feature excellent DDA and MW.

Table 3: DDA and $[\eta]$ results on commercial chitin, crustacean and arthropod shells and ionic liquid treated shells.

\begin{tabular}{|c|c|c|}
\hline Chitin source & \% DDA & $\begin{array}{c}\text { Intrinsic Viscosity } \\
{[\eta]}\end{array}$ \\
\hline shrimp $^{\mathrm{a}}$ & 95 & 1.61 \\
\hline lobster $^{\mathrm{a}}$ & 96 & 2.58 \\
\hline crab $^{\mathrm{a}}$ & 98 & 3.40 \\
\hline fly larva $^{\mathrm{a}}$ & 90 & 4.33 \\
\hline BEL $^{\mathrm{b}}$ & 74 & 2.84 \\
\hline Pretreated BEL $^{\mathrm{b}}$ & 78 & 3.00 \\
\hline Deproteinized BEL $^{\mathrm{b}}$ & 72 & 3.25 \\
\hline $\begin{array}{c}\text { Pretreated deproteinized } \\
\text { BEL }^{\mathrm{b}}\end{array}$ & 60 & 1.96 \\
\hline
\end{tabular}

a Typical experimental conditions: Samples were dried, ground, sieved, before being amorphized by milling in $\mathrm{ZrO}_{2}$ apparatus. Then 5 eq $\mathrm{NaOH}$ were added, and the mixture loaded to a PTFE jar with a $\mathrm{ZrO}_{2}$ ball, followed by aging at $98 \% \mathrm{RH}$ for 6 days at $50^{\circ} \mathrm{C}$.

${ }^{\mathrm{b}}$ Typical experimental conditions: After ionic liquid treatment, samples were mixed with 5 eq $\mathrm{NaOH}$, and loaded to a PTFE jar with a $\mathrm{ZrO}_{2}$ ball, followed by aging at $98 \% \mathrm{RH}$ for 6 days at $50^{\circ} \mathrm{C}$

\section{Energy Comparison}

Finally, we compared the energy usage of the herein disclosed milling/aging processes with a conventional solvothermal. We measured experimentally the power consumption of the mixer mill, oven, and hot plate and normalized to Joules per gram (Figure 6). Due to the size of the oven, the batch size power consumption was measured for a $240 \mathrm{~g}$ batch, whereas the solvothermal process was measured for $1 \mathrm{~g}$. When aging was conducted at RT only the milling power consumption was considered, resulting in a consumption of $3,885 \mathrm{~J} / \mathrm{g}$ for the process. When aging without pre-milling (amorphization) is conducted at $50^{\circ} \mathrm{C}$ the power consumption was $3,739 \mathrm{~J} / \mathrm{g}$. On the other hand, the solvothermal process $\left(3 \mathrm{hrs}, 133^{\circ} \mathrm{C}\right)$ required $35,748 \mathrm{~J} / \mathrm{g}$ in energy input. These values show significant favour and, potentially, bias to the aging/milling process in terms of power consumption.

To better understand the power consumption for scale-up, we theoretically modelled a batch conversion of chitin to chitosan using solvo-thermal and aging methods. We determined that solvo-thermal requires $11,467 \mathrm{KJ} / \mathrm{Kg}$, whereas aging requires between 269 and 3,885 KJ/Kg depending on conditions (Table S7).

\section{Conclusion}

In this paper we present a solvent-free method to deacetylate chitin by first amorphizing then aging, or aging alone, with $\mathrm{NaOH}$ in a humidity chamber. Increasing $\mathrm{NaOH}$ molar equivalents or temperature or time increased degree of deacetylation. We concluded that amorphization of chitin prior to deacetylation increased the extent of deacetylation under the same conditions, showing that greater access to $\mathrm{N}$-acetyl sites on chitin increases the rate of deacetylation, but that is also resulted in lower MW. While amorphisation accelerated deacetylation, it was not essential to achieve high DDA. Greater than 70\% DDA can be achieved in 6 days at room temperature or in $24 \mathrm{hrs}$ of aging at $50{ }^{\circ} \mathrm{C}$ while $95 \%$ DDA can be achieved after 3 days at $50^{\circ} \mathrm{C}$. [ $\left.\eta\right]$ of the order of 2.52 could be reached with amorphization (at RT) while absence of amorphization allowed to reach $[\eta]$ of 3.04 and 3.19 at $50{ }^{\circ} \mathrm{C}$ and RT respectively. Similarly, chitin can be directly deacetylated from shrimp, crab and lobster shell as well as fly larvae and BEL that has been pretreated with $\left[\mathrm{C}_{2} \mathrm{mim}\right][\mathrm{OAc}]$ in the same aging process,

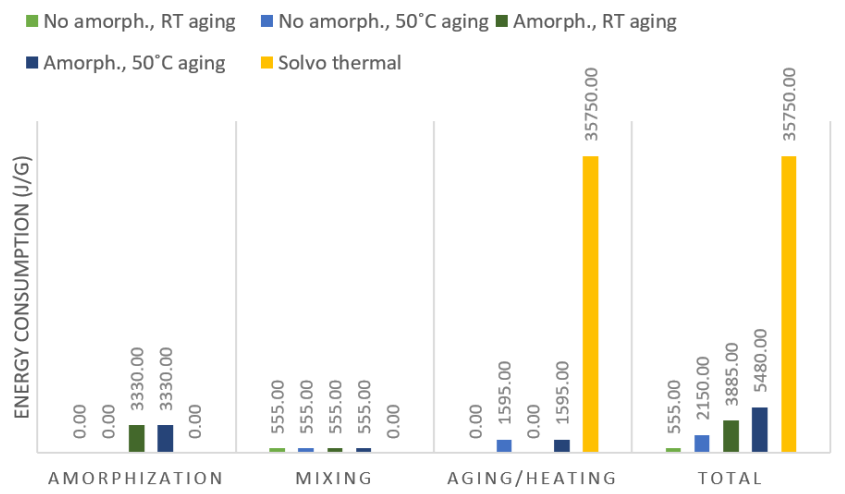

allowing to reach values for [ $\eta$ ] up to 4.33 with fly larva.

Figure 6: Breakdown of energy consumption $(\mathrm{J} / \mathrm{g})$ for mechanochemical/aging and solvothermal reactions. Reaction conditions: No amorph. corresponds to absence All aging reactions are done for 3 days; solvothermal is done for $3 \mathrm{~h}$ at $133^{\circ} \mathrm{C}$.

This method is completely novel and opens access to really large MW chitosan. Compared to known methods, it limits the reliance on materials (with excellent results at $\mathrm{NaOH}$ :chitin ratios of 4 or 5), no solvent use during reaction, and very low energy input, especially for the pure aging experiments. This method is also particularly simple to implement, requiring limited technical equipment, which is very well adapted to the Shell Biorefinery challenge of delivering solutions for the local production of high added value products close to fisheries and insect farms. In this article we also provide a proof of concept for a $10 \mathrm{~g}$ scale up of the process with excellent results. Overall this affords a new type of chitosan materials able to resist water dissolution and open access to new applications, in pollution remediation, or food packaging. 


\section{Experimental}

\section{Chemicals and methods}

Practical grade chitin, low, medium, and high molecular weight chitosan, acetic acid-d $4(\geq 99.5 \%$ D) were purchased from SigmaAldrich Co. LLC (St-Louis, MO). Medical grade chitosans were purchased from Bonding Chemical (Katy, TX). Atlantic sourced shrimp, lobster, and crab shells were purchased from a local fishery cleaned with DI water and air dried before further processing. Bombyx eri larvae (BEL) were produced from private insects rearing. After separation by extrusion, the raw chitin was cleaned with DI water, ethanol and acetone and air dried. Deproteinized BEL were obtained with $\mathrm{NaOH} 1 \mathrm{M}$ overnight under reflux and washed with DI water until neutral $\mathrm{pH}$. NaOH micropearls were purchased from Acros Organics (Belgium). Deuterium oxide $(99.9 \%$ D) was purchased from Cambridge Isotope Laboratories, Inc (Andover, MA). Methanol, sodium chloride, sodium acetate, and acetic acid (all reagent grade) were purchased from ACP (Montreal, Qc., Canada). Potassium bromide Spectrosol was purchased from VWR (Mount-Royal, Quebec). Potassium sulfate and potassium carbonate were purchased from Alfa Aesar (Ward Hill, MA). $\left[\mathrm{C}_{2} \mathrm{mim}\right][\mathrm{OAc}]$ was purchased from Iolitech (Tuscaloosa, $\mathrm{Al}$ ). Pullulan calibration Readycal Kit (Mp 180 - 1220000 Da) was purchased from PSS polymers (Germany).

\section{Milling}

In the following procedures, a Retsch MM 400 was used as mixer mill, with jars made of polytetrafluoroethylene (PTFE), $20 \mathrm{~mL}$, stainless steel $(10 \mathrm{~mL})$ or zirconia $(10 \mathrm{~mL})$, equipped with balls of zirconia or steel.

\section{Controlled humidity chamber}

In aging experiments described below, controlled humidity chambers were used. Three relative humidity (RH) levels were tested $(43 \%, 75 \%, 98 \%)$. The chamber consisted of a $100 \mathrm{~mL}$ glass screw top jar. The chamber is filled with $20 \mathrm{~mL}$ of saturated aqueous solutions of $\mathrm{K}_{2} \mathrm{CO}_{3}, \mathrm{NaCl}$ and $\mathrm{K}_{2} \mathrm{SO}_{4}$, to access $43 \%$, $75 \%$, and $98 \% \mathrm{RH}$ respectively. An open 4 dram vial, containing the solid state sample, was placed inside the chamber. The overall chamber could be heated by placing in a Fisher Scientific Isotemp oven.

\section{Conventional solvothermal chitin deacetylation experiments}

For comparison purposes, chitosan samples were prepared by a traditional method ${ }^{27}$ for comparison by heating for 3 hours in $50 \% \mathrm{NaOH}$ solution at $133^{\circ} \mathrm{C}$.

\section{Mixer-mill based chitin deacetylation experiments}

In a typical experiment, $105 \mathrm{mg}$ of chitin and $95 \mathrm{mg}$ of $\mathrm{NaOH}$ (1:5 chitin: $\mathrm{NaOH}$ ratio) were combined in a PTFE jar and milled for 30, 60 or 90 minutes with one zirconia ball (10 mm). Milling mixture mass was always maintained to be $200 \mathrm{mg}$. For example, with a $1: 1$ chitin: $\mathrm{NaOH}$ ratio, $170 \mathrm{mg}$ of chitin and $30 \mathrm{mg}$ of $\mathrm{NaOH}$ were used. Post milling, the samples were worked up by washing and filtering with methanol until neutral $\mathrm{pH}$ using Whatman filter paper $(\# 1,55 \mathrm{~mm})$, then air dried.

\section{Mechanochemical amorphization of chitin}

In a typical experiment, commercial chitin $(200 \mathrm{mg})$ was placed in a zirconia jar equipped with one zirconia ball $(10 \mathrm{~mm})$ and milled in a mixer mill for $30 \mathrm{mins}$ in a at $29.5 \mathrm{~Hz}$. The resulting powder was used as is for analysis or further mechanochemical or aging treatments.

\section{Chitin deacetylation experiments by aging}

In the following, chitin samples are used as is, or after a first step of mechanochemical amorphization (vide supra). In a typical experiment, $105 \mathrm{mg}$ of chitin and $95 \mathrm{mg}$ of $\mathrm{NaOH}(1: 5$ chitin: $\mathrm{NaOH}$ ratio) were combined in a PTFE jar and milled for 5 minutes with one zirconia ball $(10 \mathrm{~mm})$. The procedure was similar with other chitin: $\mathrm{NaOH}$ ratios, and the total reagent mass of solid was kept at $200 \mathrm{mg}$. The mixture, a very pale-yellow powder was transferred from the jar to an open 4 dram glass vial and aged in a controlled humidity chamber for 1 to 6 days at constant temperatures from room temperature to $50^{\circ} \mathrm{C}$. Post aging, the samples were worked up by washing and filtering with $100 \mathrm{~mL}$ of methanol until neutral $\mathrm{pH}$ using Whatman filter paper (\# 1, 55mm), then air dried. Controlled experiments were run exactly as stated above, in absence of $\mathrm{NaOH}$, or in absence of controlled humidity (achieved by sealing the sample in a glass vial during the aging period).

\section{Scale-Up - Chitin deacetylation experiments by aging}

For 100x scale-up, commercial chitin (10 g) was milled with $\mathrm{NaOH}(9 \mathrm{~g})$ in a planetary mill for 5 minutes in $\mathrm{ZrO}_{2}(50 \mathrm{~mL})$ and stainless steel $(80 \mathrm{~mL})$ with 5 balls $(10 \mathrm{~mm})$ of the same material as the jar. The mixture was then placed in a petri dish $(115 \mathrm{~mm} \times 65 \mathrm{~mm})$ which was placed in a sealed $1 \mathrm{~L}$ container containing $100 \mathrm{~mL}$ of saturated $\mathrm{K}_{2} \mathrm{SO}_{4}$ salt solution with excess salt. The containers were placed in the oven to age at $50^{\circ} \mathrm{C}$ for 3 and 6 days. Post aging, the samples were worked up by washing and filtering with methanol until neutral $\mathrm{pH}$ using Whatman filter paper (\# 1, 55mm), then air dried.

\section{Pre-treatment of biomass samples}

Shrimp, lobster, crab and fly larva shell samples were ground using a Bel-Art Products micro-mill for 2 mins then sieved using U.S.A standard test sieves, where particle $<125 \mu \mathrm{m}$ were collected and used for the deacetylation process. The resulting powder was used as is for further treatment, namely mechanochemical amorphization and aging-based deacetylation.

\section{Ionic liquid pretreatment of biomass sample}

Biomass of BEL were treated with $\left[\mathrm{C}_{2} \mathrm{mim}\right][\mathrm{OAc}]$ for $40 \mathrm{mins}$ at $110^{\circ} \mathrm{C}$. The chitin suspension was then cooled in an ice bath and washed with deionized water, centrifuged at $10733 \mathrm{~g}$ for 20 mins. The supernatant was removed, the resulting mass was then filtered, re-washed and refiltered. ${ }^{73}$

\section{Control experiments \\ Manual grinding}

A 1:5 chitin: $\mathrm{NaOH}$ mixture containing $105 \mathrm{mg}$ of chitin and 95 $\mathrm{mg}$ of $\mathrm{NaOH}$ was manually ground in an agate mortar and pestle 
for 1 minute to homogenize. The mixture was then aged in an open vial in 43,75 , and $98 \% \mathrm{RH}$ at $50^{\circ} \mathrm{C}$ and worked up as described previously.

\section{$\mathrm{No} \mathrm{NaOH}$}

A $200 \mathrm{mg}$ chitin samples was milled for 5 minutes in an PTFE jar with $\mathrm{ZrO}_{2}$ ball. The mixture was then aged in an open vial in $98 \% \mathrm{RH}$ at $50^{\circ} \mathrm{C}$ and worked up as described previously.

\section{No humidity}

A 1:5 chitin: $\mathrm{NaOH}$ mixture containing $105 \mathrm{mg}$ of chitin and 95 mg of $\mathrm{NaOH}$ was milled for 5 minutes in an PTFE jar with $\mathrm{ZrO}_{2}$ ball. The mixture was then aged in a sealed vial at $50^{\circ} \mathrm{C}$ and worked up as described previously.

\section{Analysis - Characterization - equipment details and methods ${ }^{13}$ C Magic Angle Spinning nuclear magnetic resonance (MAS- NMR)}

NMR spectra were recorded on a Varian VNMRS operating at $400 \mathrm{MHz}$ for the solid-state ${ }^{13} \mathrm{C}$ acquisition using a $4 \mathrm{~mm}$ doubleresonance Varian Chemagnetics T3 probe. A contact time of $1000 \mu \mathrm{s}$ and a recycle delay of $3 \mathrm{~s}$ were used to acquire quantitative spectra. ${ }^{74} 2872$ scans were acquired of each sample for a total time of $2.5 \mathrm{hrs}$. DDA was calculated using a known method. ${ }^{75}$

\section{${ }^{1} \mathrm{H} N M R$}

NMR spectra were recorded on a Varian VNMRS spectrometer operating at $500 \mathrm{MHz}$ for $1 \mathrm{H}$ acquisitions. DDA was calculated using a known method ${ }^{63}$ when samples were soluble in dilute acetic acid.

\section{IR}

IR spectra were recorded using a Perkin-Elmer Spectrum 400 for 64 scans from $4000 \mathrm{~cm}^{-1}$ to $400 \mathrm{~cm}^{-1}$ in transmission mode from pressed $\mathrm{KBr}$ discs where, $2 \mathrm{mg}$ of sample was mixed with 200 $\mathrm{mg}$ of $\mathrm{KBr}$. DDA was calculated by comparing the by comparing the absorption of the amide band at $1655 \mathrm{~cm}^{-1}$ and the hydroxyl absorption band at $3450 \mathrm{~cm}^{-1}$ as the reference peak using the equation, $\% \mathrm{~N}$-acetylation $=(\mathrm{A} 1655 / \mathrm{A} 3450) \times 115 .^{76}$

\section{pXRD}

Sample diffractogram was recorded from $5^{\circ}$ to $40^{\circ}$ on a zerobackground plate using a Bruker D8 ADVANCE X-Ray Diffractometer equipped using $\mathrm{Cu}-\mathrm{Ka}(\lambda=1.54 \AA$ ) $)$ source. Chitin crystallinity was determined by comparing the entire area of the diffractogram (global area) and the area of the peaks (reduced area). Where \%Crystallinity $=100-\%$ Amorphous and $\%$ Amorphous $=[($ Global Area - Reduced Area $) /$ Global Area $] \mathrm{x}$ $100 .{ }^{77}$

\section{GPC}

We used an Agilent Technologies 1260 Infinity II GPC triple detection equipped with Shodex OHpak SB-804 HQ 300 x 8 mm, $10 \mu \mathrm{m}$ column which was calibrated with a PSS Polymers Readycal Kit pullulan standard in an acetic acid buffer system
(0.3M Acetic Acid, 0.2M Sodium Acetate and 0.8mM Sodium Azide).

Samples were left to solubilize in an acetic acid buffer by shaking at room temperature for two days then filtered through a $0.45 \mu \mathrm{m}$ PTFE filter. The filter was pre-weighed prior to filtration, then dried and weighed post filtration to determine the amount of insoluble material.

\section{Viscosity}

Viscosity was measured as an average of 6 repetitions at $40^{\circ}$ incline using Anton Paar AMVn automated micro viscometer with $1.6 \mathrm{~mm}$ capillary ad $1.5 \mathrm{~mm}$ stainless steel ball at $35^{\circ} \mathrm{C}$. Sample viscosity was measured and used determine intrinsic viscosity $[\eta]$. A typical sample was prepared by dissolving chitosan or chitin in $\left[\mathrm{C}_{2} \mathrm{mim}\right][\mathrm{OAc}]$ in concentrations of 3 $\mathrm{mg} / \mathrm{mL}$ and lower at $80^{\circ} \mathrm{C}$ for two days in a sand bath, yielding a golden amber solution. Since filtration was not possible due to viscosity, the samples were centrifuged at 3000 RPM for 10 minutes to remove any undissolved material. Each sample was measured at 5 decreasing concentrations for determination of intrinsic viscosity.

\section{Density}

Density was measured using Anton Paar DMA 38 density meter using the method described by the company in the user manual.

\section{Energy Measurements}

Power consumption was measured using a P3 P3IP4400, Kill A Watt electricity usage monitor. Several hours or days of run time power consumption were measured for each, the mill, hot plate and the oven, while in experimental use. The overall power consumption was averaged to $\mathrm{W} / \mathrm{min} / \mathrm{g}$ based on experimental conditions of each process.

\section{Energy Calculations}

Theoretical power consumption was calculated based on heating the required amounts of water, $\mathrm{NaOH}$ and chitin, using heat capacity, to the final desired temperatures for each process, including the enthalpy of dissolution for $\mathrm{NaOH}$ and without heat losses of the system. For mechanochemical energy, we did not have any scale-up data so we used values obtained experimentally from the mixer-mill which may yield higher energy consumption than if appropriate scale equipment is used. The energy difference for chitin deacetylation was ignored as its effect is considered the same for all situations.

\section{Conflicts of interest}

There are no conflicts to declare.

\section{Acknowledgements}

We thank the Natural Science and Engineering Research Council of Canada (NSERC) Discovery Grant program, the Canada 
Foundation for Innovation (CFI), the Canada Research Chairs (CRC), the Fonds de Recherche du Québec - Nature et Technologies (FRQNT) Equipe program, the Centre for Green Chemistry and Catalysis (CGCC), McGill University for their financial support. We are grateful to Robin Stein for solid state and solution NMR help. We'd like to thank Catherine King, Jean-Louis Do, Hatem Titi, Alain Li and Petr Fiurasek for help and discussions, as well as Blaine Fiss for milling and biomass discussions.

\section{Notes and references}

\$ Footnotes relating to the main text should appear here. These might include comments relevant to but not central to the matter under discussion, limited experimental and spectral data, and crystallographic data.

J. H. Clark, A. J. Hunt, L. Moity and J. Sherwood, in Green and Sustainable Medicinal Chemistry: Methods, Tools and Strategies for the 21st Century Pharmaceutical Industry, eds. L. Summerton, H. F. Sneddon, L. C. Jones and J. H. Clark, The Royal Society of Chemistry, Cambridge, 2016, pp. $28-40$ K. Kümmerer and J. Clark, Sustain. Sci., 2016, 43-59. T. Puranen, M. Alapuranen and J. Vehmaanperä, Biotechnol. Biol. Trichoderma, 2014, 351-362.

$4 \quad$ S. Kim, Chitin, Chitosan, Oligosaccharides and Their Derivatives, CRC Press, London, 2010.

5 A. Percot, C. Viton and A. Domard, Biomacromolecules, 2003, 4, 12-18.

$6 \quad$ N. Yan and X. Chen, Nature, 2015, 524, 155-157.

$7 \quad$ X. G. Chen, L. Zheng, Z. Wang, C. Y. Lee and H. J. Park, J. Agric. Food Chem., 2002, 50, 5915-5918.

8 Q. Gan and T. Wang, Colloids Surfaces B Biointerfaces, 2007, 59, 24-34.

9 L. Bekale, D. Agudelo and H. A. Tajmir-Riahi, Colloids Surfaces B Biointerfaces, 2015, 125, 309-317.

10 S. H. Hsu, S. W. Whu, C. L. Tsai, Y. H. Wu, H. W. Chen and K. H. Hsieh, J. Polym. Res., 2004, 11, 141-147.

11 N. Nwe, T. Furuike and H. Tamura, Materials, 2009, 2, 374-398.

12 S. H. Chang, H. T. V. Lin, G. J. Wu and G. J. Tsai, Carbohydr. Polym., 2015, 134, 74-81.

13 A. J. Al-Manhel, A. R. S. Al-Hilphy and A. K. Niamah, J. Saudi Soc. Agric. Sci., , DOI:10.1016/j.jssas.2016.04.001.

14 Q. Yuan, J. Shah, S. Hein and R. D. K. Misra, Acta Biomater., 2010, 6, 1140-1148.

15 N. Bhattarai, J. Gunn and M. Zhang, Adv. Drug Deliv. Rev., 2010, 62, 83-99.

16 Q. Yuan, S. Hein and R. D. K. Misra, Acta Biomater., 2010, 6, 2732-2739.

17 A. Jimtaisong and N. Saewan, Int. J. Cosmet. Sci., 2014, 36 , 12-21.

18 B. Worm, H. K. Lotze, I. Jubinville, C. Wilcox and J. Jambeck, Annu. Rev. ofEnvironment Resour. Plast., 2017, 42, 1-26.

19 J. G. Fernandez and D. E. Ingber, Macromol. Mater. Eng., 2014, 299, 932-938.

20 M. Lee, B.-Y. Chen and W. Den, Appl. Sci., 2015, 5, 1272 1283.
Rasoulianboroujeni, H. Koturi and L. Tayebi, Mater. Res. Innov., 2018, 22, 177-181.

I. Younes and M. Rinaudo, Mar. Drugs, 2015, 13, 1133 1174.

N. Okafor, BBA - Mucoproteins Mucopolysaccharides, 1965, 101, 193-200.

A. M. Striegel, Carbohydr. Polym., 1997, 34, 267-274. J. Jung and Y. Zhao, Carbohydr. Res., 2011, 346, 1876 1884.

A. Domard and M. Rinaudo, Int. J. Biol. Macromol., 1983, 5, 49-52.

K. L. B. Chang, G. Tsai, J. Lee and W. R. Fu, Carbohydr. Res., 1997, 303, 327-332.

T. Sannan, K. Kurita and Y. Iwakura, Die Makromol. Chemie, 1976, 177, 3589-3600.

M. Anwar, A. S. Anggraeni and M. H. Al Amin, AIP Conf. Proc., , DOI:10.1063/1.4978144.

T. S. Tan, H. Y. Chin, M. L. Tsai and C. L. Liu, Carbohydr Polym., 2015, 122, 321-328.

S. V. Nemtsev, A. I. Gamzazade, S. V. Rogozhin, V. M. Bykova and V. P. Bykov, Appl. Biochem. Microbiol., 2002, 38, 521-526.

C. T. G. V. M. T. Pires, J. A. P. Vilela and C. Airoldi, Procedia Chem., 2014, 9, 220-225.

H. K. No, Y. I. Cho, H. R. Kim and S. P. Meyers, 2000, 48, 2625-2627.

A. Sahu, P. Goswami and U. Bora, J. Mater. Sci. Mater. Med., 2009, 20, 171-175.

X. Chen, H. Yang, Z. Zhong and N. Yan, Green Chem., 2017, 19, 2783-2792.

S. L. James, C. J. Adams, C. Bolm, D. Braga, P. Collier, T. Friščić, F. Grepioni, K. D. M. Harris, G. Hyett, W. Jones, A. Krebs, J. Mack, L. Maini, A. G. Orpen, I. P. Parkin, W. C. Shearouse, J. W. Steed and D. C. Waddell, Chem. Soc. Rev., 2012, 41, 413-447.

C. Xu, S. De, A. M. Balu, M. Ojeda and R. Luque, Chem. Commun., 2015, 51, 6698-6713.

X. Chen, Y. Liu, F. M. Kerton and N. Yan, $R S C A d v$., 2015, 5, 20073-20080.

T. Kleine, J. Buendia and C. Bolm, Green Chem., 2013, 15, 160-166.

G. Margoutidis, V. H. Parsons, C. S. Bottaro, N. Yan and F M. Kerton, ACS Sustain. Chem. Eng., 2018, 6, 1662-1669. C. Mottillo, Y. Lu, M.-H. Pham, M. J. Cliffe, T.-O. Do and T. Friščić, Green Chem., 2013, 15, 2121

M. J. Cliffe, C. Mottillo, R. S. Stein, D.-K. Bučar and T. Friščić, Chem. Sci., 2012, 3, 2495.

C. Mottillo and T. Friščić, Molecules, 2017, 22, 144 , DOI:10.3390/molecules22010144.

R. D. Rogers, Chem. Eng. News, 2015, 93, 42-43.

M. D. P. Buera, G. Levi and M. Karel, Biotechnol. Prog., 1992, 8, 144-148.

X. Chen, H. Yang and N. Yan, Chem. - A Eur. J., 2016, 22, 13402-13421.

J. L. Do and T. Friščić, ACS Cent. Sci., 2017, 3, 13-19.

T. Friščić, S. L. Childs, R. S. A. A. and W. Jones, CrystEngComm, 2009, 11, 418-426.

T. Friščić, A. V. Trask, W. Jones and W. D. S. Motherwell, Angew. Chemie - Int. Ed., 2006, 45, 7546-7550.

T. Friščić, D. G. Reid, I. Halasz, R. S. Stein, R. E. Dinnebier and M. J. Duer, Angew. Chemie - Int. Ed., 2010, 49, 712-715.

Y. Wu, T. Sasaki, S. Irie and K. Sakurai, Polymer (Guildf)., 2008, 49, 2321-2327.

X.-G. Chen, L. Zheng, Z. Wang, C.-Y. Lee and H.-J. Park, J. Agric. Food Chem, 2002, 50, 5915-5918. 

Rasoulianboroujeni, H. Koturi and L. Tayebi, Mater. Res. Innov., 2016, 8917, 1-5.

O. A. Battista, Ind. Eng. Chem., 1950, 42, 502-507.

55 M. Ioelovich, J. Chem., 2014, 3, 7-14.

56 A. Martinou, D. Kafetzopoulos and V. Bouriotis, Carbohydr. Res., 1995, 273, 235-242.

R. H. Chen and H. D. Hwa, Carbohydr. Polym., 1996, 29, 353-358.

58 J. M. Andersen and J. Mack, Chem. Sci., 2017, 8, 54475453.

59 J. F. V. Vincent and U. G. K. Wegst, Arthropod Struct. Dev., 2004, 33, 187-199.

60 G. Cárdenas, G. Cabrera, E. Taboada and S. P. Miranda, J. Appl. Polym. Sci., 2004, 93, 1876-1885.

61 S. Hajji, I. Younes, O. Ghorbel-Bellaaj, R. Hajji, M. Rinaudo, M. Nasri and K. Jellouli, Int. J. Biol. Macromol., 2014, 65, 298-306.

62 M. A. García, N. de la Paz, C. Castro, J. L. Rodríguez, M. Rapado, R. Zuluaga, P. Gañán and A. Casariego, J. Radiat. Res. Appl. Sci., 2015, 8, 190-200.

63 M. N. V. Ravi Kumar, React. Funct. Polym., 2000, 46, 127.

64 P. J. V. A. N. Duin, J. J. Hermans and L. Anorganische, 1959, 26, 295-304.

65 A. M. Striegel, Carbohydr. Polym., 1997, 34, 267-274.

66 Y. Qin, X. Lu, N. Sun and R. D. Rogers, Green Chem., 2010, 12, 968.

67 P. S. Barber, S. P. Kelley, C. S. Griggs, S. Wallace and R. D. Rogers, Green Chem., 2014, 16, 1828-1836.

68 J. L. Shamshina, O. Zavgorodnya, J. R. Bonner, G. Gurau, T. Di Nardo and R. D. Rogers, ChemSusChem, 2017, 10, 106-111.

69 E. N. Chebotok, V. Y. Novikov and I. N. Konovalova, Russ. J. Appl. Chem., 2006, 79, 1162-1166.

S. Nguyen, S. Hisiger, M. Jolicoeur, F. M. Winnik and M. D. Buschmann, Carbohydr. Polym., 2009, 75, 636-645. E. L. Mogilevskaya, T. A. Akopova, A. N. Zelenetskii and A. N. Ozerin, Polym. Sci. Ser. A, 2006, 48, 116-123.

P. Lertsutthiwong, N. C. How and S. Chandrkrachang, $J$. Met. Mater. Miner., 2002, 12, 11-18.

73 E. Husson, C. Hadad, G. Huet, S. Laclef, D. Lesur, V. Lambertyn, A. Jamali, S. Gottis, C. Sarazin and A. NguyenVan Nhien, Green Chem., 2017, 4122-4131. L. Raymond, F. G. Morin and R. H. Marchessault, Carbohydr. Res., 1993, 246, 331-336. A. Pelletier, J. Sygusch, E. Chornet and R. P. Overend, 1992, 55, 1175-1176.

76 A. Baxter, M. Dillion, K. Taylor and G. Roberts, Int. J. Biol. Macromol., 1992, 14, 166-169.

S. Park, J. O. Baker, M. E. Himmel, P. A. Parilla and D. K. Johnson, Biotechnol. Biofuels, 2010, 3, 1-10. 
Electronic Supplementary Information

\title{
Deacetylation by mechanochemistry and aging as a pathway to high molecular weight chitosan from chitin
}

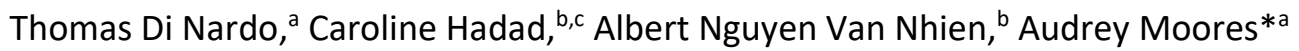

\section{Table of Contents}

Table S1: Comparison of known deacetylation techniques.

Figure S1: FTIR spectra of commercial chitin pre and post amorphization in $\mathrm{ZrO}_{2}$ jar with

$\mathrm{ZrO}_{2}$ ball for 30 minutes milling.

Figure S2: IR spectra of commercial chitin, commercial chitosan, and chitosan produced with the aging process at room temperature, $98 \% \mathrm{RH} 1: 5$ chitin: $\mathrm{NaOH}$. The amide peak at $1655 \mathrm{~cm}^{-1}$ is measured in reference to the hydroxyl peak at $3450 \mathrm{~cm}^{-1}$.

Figure S3: Solid-State ${ }^{13} \mathrm{C}$ NMR spectra of commercial chitin, commercial chitosan, and chitosan produced with the aging process at room temperature. DDA is calculated by comparing the methyl peak at 22 ppm to a reference C1 carbon peak at $104 \mathrm{ppm}$.

Figure S4: Pictures of aged chitosan (from left to right) in 1\% acetic acid, $2 \%$ acetic acid, buffer solution ( $0.3 \mathrm{M}$ acetic acid, $0.25 \mathrm{M}$ sodium acetate, $0.8 \mathrm{mM}$ sodium azide), $0.8 \%$ lactic acid and [ $\left.\mathrm{C}_{2} \mathrm{mim}\right][\mathrm{OAc}]$ pre (left) and post (right) heating $\left(80^{\circ} \mathrm{C}\right.$. Images show that the age based chitosan only dissolves in [ $\left.\mathrm{C}_{2} \mathrm{mim}\right][\mathrm{OAc}]$.

Figure S5: Effect of the chitin: $\mathrm{NaOH}$ ratio on [ $\eta$ ] and DDA in the amorphization/aging based chitin deacetylation experiments. Conditions of scheme 2 with aging at $50^{\circ} \mathrm{C}$ for 6 days. [ ] not measured for $1: 1,1: 2$ and 1:3 chitin: $\mathrm{NaOH}$ ratios.

Table S2: Initial DDA of commercial chitin, commercial chitosan and solution deacetylated chitosan acquired by ${ }^{13} \mathrm{C}$ CP MAS NMR . 7

Table S3: Mixer-mill based commercial chitin deacetylation experiments in PTFE jar with a $\mathrm{ZrO}_{2}$ ball. DDA $=[\mathrm{H}] /([\mathrm{COMe}]+[\mathrm{H}]) \times 100$, determined by ${ }^{13} \mathrm{C}$ CP MAS NMR. LAG solvent 10 wt\%: none, dichloromethane, acetonitrile, ethyl acetate, methanol, ethanol and deionized water.

Table S4: Table of the relative humidity $(\mathrm{RH})$ study of aging of crystalline chitin for 6 days at $22^{\circ} \mathrm{C}$ with a chitin to $\mathrm{NaOH}$ ratio of $1: 5$. 
Table S5: DDA and [ $\eta$ ] of commercial chitin treated with or without amorphization pretreatment ( 30 min milling in $\mathrm{ZrO}_{2}$ apparatus) followed by 3 to 6 days aging at 22 to $50^{\circ} \mathrm{C}$, at $98 \%$ humidity and with a chitin to $\mathrm{NaOH}$ ratio of $1: 5$.

Table S6: DDA and [ $\eta$ ] of commercial chitin treated with amorphization pre-treatment (30 min milling in $\mathrm{ZrO}_{2}$ apparatus) followed by 6 days aging at $50^{\circ} \mathrm{C}$, at $98 \%$ humidity and with a chitin to $\mathrm{NaOH}$ ratio ranging from $1: 1$ to $1: 5$......

Table S7: Energy consumption comparison of solvo-thermal and aging methods for deacetylation of $1 \mathrm{Kg}$ of chitin into chitosan. Solvothermal was calculated for heating $1 \mathrm{Kg}$ of chitin, $18.5 \mathrm{Kg}$ of water, and $18.5 \mathrm{Kg}$ of $\mathrm{NaOH}$ to $133^{\circ} \mathrm{C}$. Aging was calculated for heating $1 \mathrm{Kg}$ of chitin, $2 \mathrm{Kg}$ of water, and $0.9 \mathrm{Kg}$ of $\mathrm{NaOH}$. Amorphization includes 30 mins of milling in $\mathrm{ZrO}_{2}$ jar with $\mathrm{ZrO}_{2}$ ball. Mixing requires 5 mins milling in PTFE jar with one $\mathrm{ZrO}_{2}$ ball.

Table S1: Comparison of known deacetylation techniques.

\begin{tabular}{|c|c|c|c|c|c|}
\hline Method & Conditions & $\begin{array}{l}\mathrm{NaOH} \\
\text { equivalents }\end{array}$ & MW & DDA & Ref \\
\hline $\begin{array}{l}\text { Solvo- } \\
\text { Thermal }\end{array}$ & $\begin{array}{l}50 \% \\
\mathrm{NaOH}_{(\mathrm{aq})}, \mathrm{RT}- \\
140^{\circ} \mathrm{C}, 3^{\mathrm{a}}- \\
540 \mathrm{Hrs}^{\mathrm{b}}\end{array}$ & 42 & Varied & $70-99 \%$ & $\begin{array}{l}\text { C. Rong Huei, Carbohydr. Polym., 1996, } \\
\text { 29, 353-358. } \\
\text { A. Domard and M. Rinaudo, Int. J. Biol. } \\
\text { Macromol., 1983, 5, 49-52. } \\
\text { A. Alimuniar, and R. Zainuddin, In } \\
\text { Advances in Chitin and Chitosan, C.J. } \\
\text { Beine, P.A. Sanford and J.P. Zikakis } \\
\text { (eds.), Elsevier Applied Science, London } \\
\text { and New York, pp. 627-632, 1992. }\end{array}$ \\
\hline
\end{tabular}




\begin{tabular}{|c|c|c|c|c|c|}
\hline $\begin{array}{l}\text { Planetary } \\
\text { Milling }\end{array}$ & $\begin{array}{l}1: 5 \\
\text { chitin: } \mathrm{NaOH}, \\
100 \text { balls } \\
\mathrm{ZrO}_{2}^{2 \mathrm{rO}}, 80 \\
\text { mins }\end{array}$ & 5 & 1-13 kDa & $80 \%$ & $\begin{array}{l}\text { X. Chen, H. Yang, Z. Zhong and N.Yan, } \\
\text { Green Chem., 2017, 19, 2783-2792. }\end{array}$ \\
\hline Microwave & $\begin{array}{l}45 \% \\
\mathrm{NaOH}_{(\mathrm{aq})}, 5.5 \\
\text { Mins, } 900 \mathrm{~W}\end{array}$ & 31 & $85 \mathrm{kDa}$ & $80 \%$ & $\begin{array}{l}\text { A. Sahu, P. Goswami and U. Bora, J. } \\
\text { Mater. Sci. Mater. Med., , } \\
\text { DOI:10.1007/s10856-008-3549-4. }\end{array}$ \\
\hline Sonication & $\begin{array}{l}60 \% \\
\mathrm{NaOH}_{(\mathrm{aq})}, 30 \\
\text { mins, } 500 \mathrm{~W}\end{array}$ & $>16$ & Degradation & $73 \%$ & $\begin{array}{l}\text { M. Anwar, A. S. Anggraeni and M. H. Al } \\
\text { Amin, AIP Conf. Proc. } \\
\text { DOI:10.1063/1.4978144. }\end{array}$ \\
\hline $\begin{array}{l}\text { High } \\
\text { Pressure } \\
\text { Run }\end{array}$ & $\begin{array}{l}50 \% \\
\mathrm{NaOH}_{(\mathrm{aq})} \\
120^{\circ} \mathrm{C}, 15 \mathrm{PSI}\end{array}$ & 41 & 1466 kDa & $90 \%$ & $\begin{array}{l}\text { H. K. No, Y. I. Cho, H. R. Kim and S. P. } \\
\text { Meyers, J. Agric. Food Chem., 2000, 48, } \\
\text { 2625-2627. }\end{array}$ \\
\hline Maceration & $\begin{array}{l}7 \text { days, } 80 \% \\
\mathrm{NaOH}_{(\mathrm{aq})}\end{array}$ & 22 & $\mathrm{~N} / \mathrm{A}$ & $80 \%$ & $\begin{array}{l}\text { M. Anwar, A. S. Anggraeni and M. H. Al } \\
\text { Amin, AIP Conf. Proc. } \\
\text { DOI:10.1063/1.4978144. }\end{array}$ \\
\hline $\begin{array}{l}\text { Freeze } \\
\text { thaw }\end{array}$ & $24 \% \mathrm{NaOH}$ & $>13$ & $180-300 \mathrm{kDa}$ & $80-95 \%$ & $\begin{array}{l}\text { S. V. Nemtsev, A. I. Gamzazade, S. V. } \\
\text { Rogozhin, V. M. Bykova and V. P. Bykov, } \\
\text { Appl. Biochem. Microbiol., 2002, 38, } \\
\text { 521-526. }\end{array}$ \\
\hline This work & $\begin{array}{l}\text { Milling for } \\
30 \text { min } \\
\text { followed by } \\
6 \text { days of } \\
\text { aging }\end{array}$ & 5 & N/A & $80-95 \%$ & \\
\hline
\end{tabular}




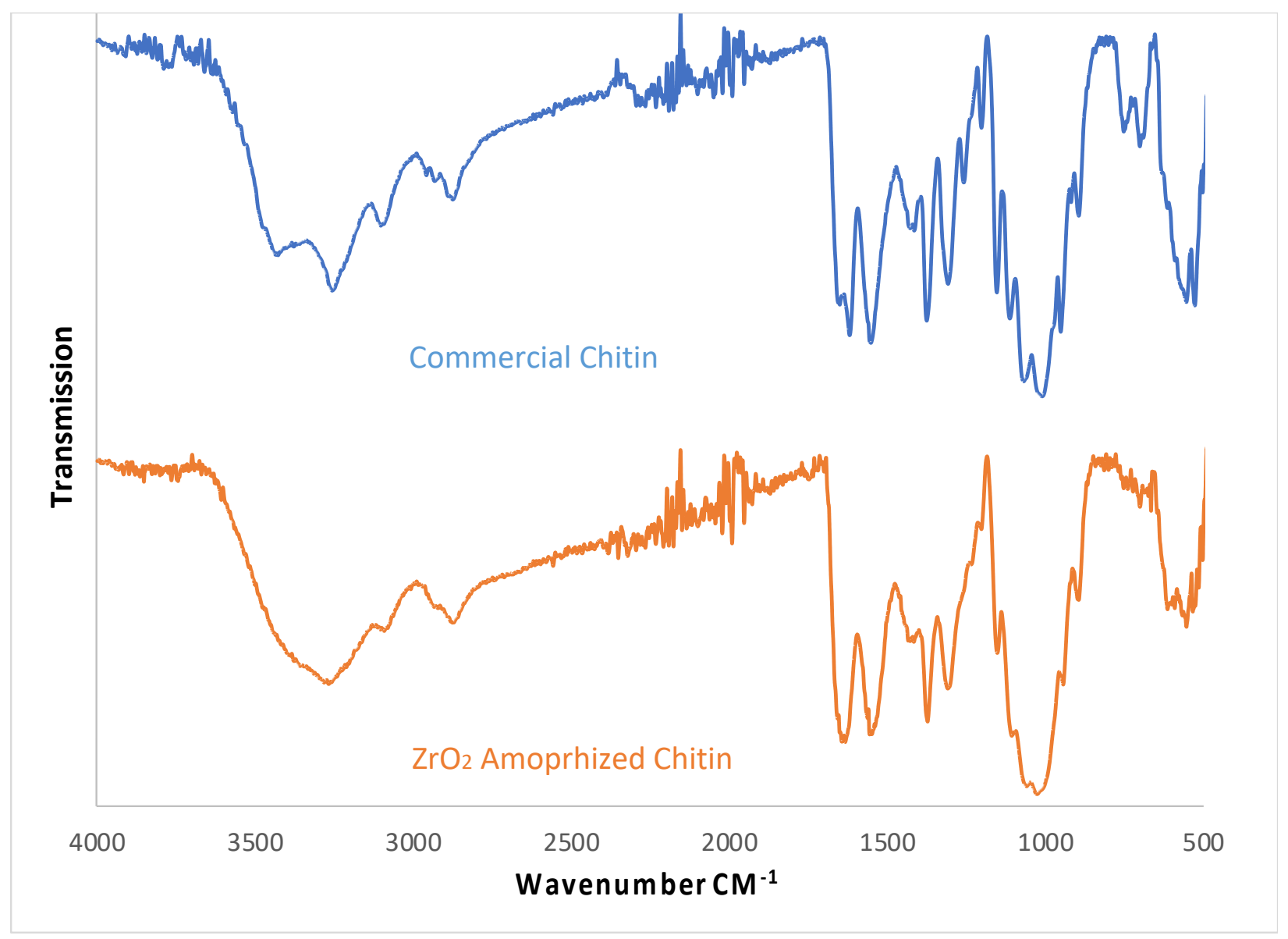


Figure S1: FTIR spectra of commercial chitin pre and post amorphization in $\mathrm{ZrO}_{2}$ jar with $\mathrm{ZrO}_{2}$ ball for 30 minutes milling.

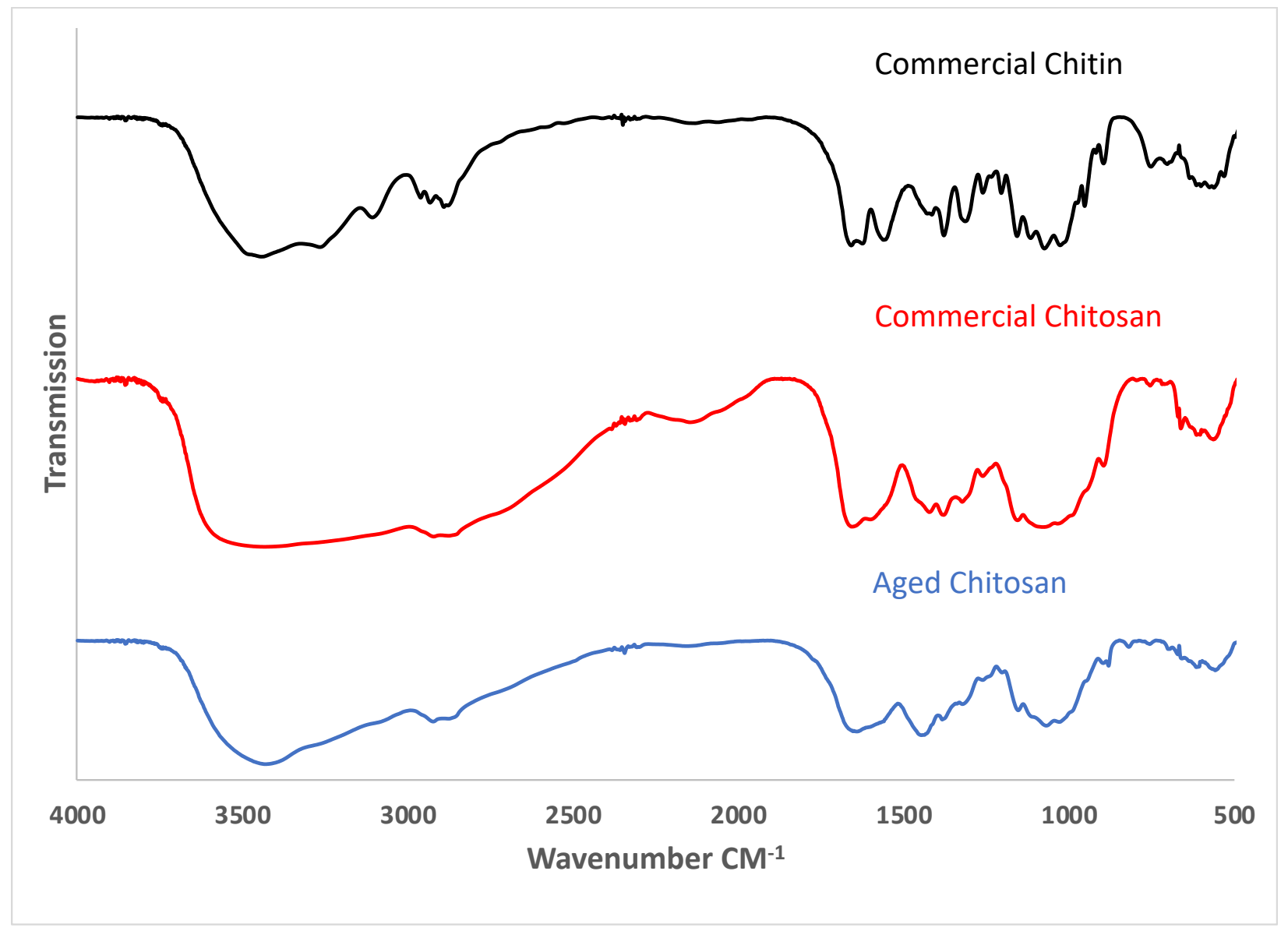

Figure S2: IR spectra of commercial chitin, commercial chitosan, and chitosan produced with the aging process at room temperature, $98 \% \mathrm{RH} 1: 5$ chitin: $\mathrm{NaOH}$. The amide peak at $1655 \mathrm{~cm}^{-1}$ is measured in reference to the hydroxyl peak at $3450 \mathrm{~cm}^{-1}$. 


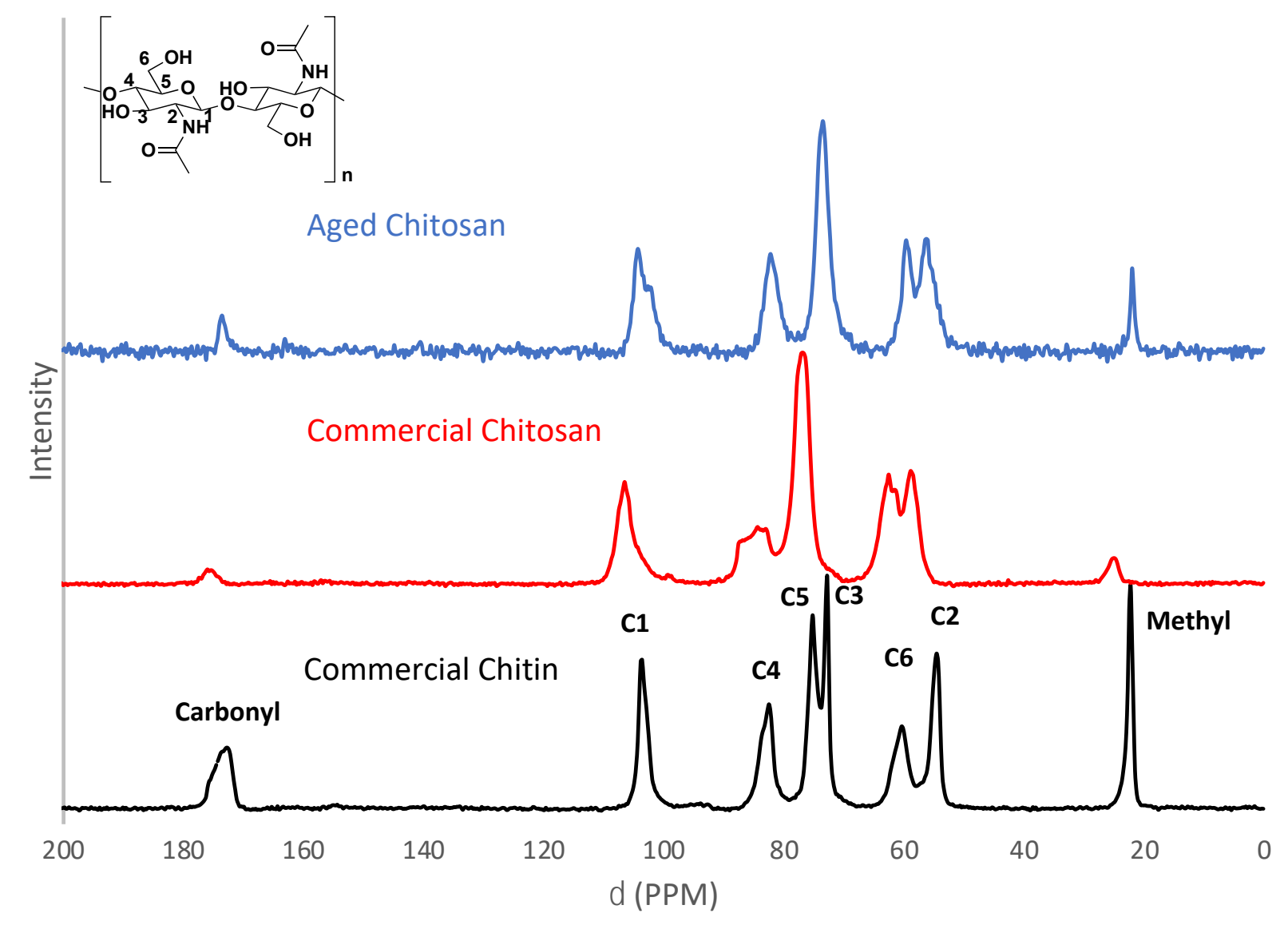

Figure S3: Solid-State ${ }^{13} \mathrm{C}$ NMR spectra of commercial chitin, commercial chitosan, and chitosan produced with the aging process at room temperature. DDA is calculated by comparing the methyl peak at 22 ppm to a reference C1 carbon peak at 104 ppm. 


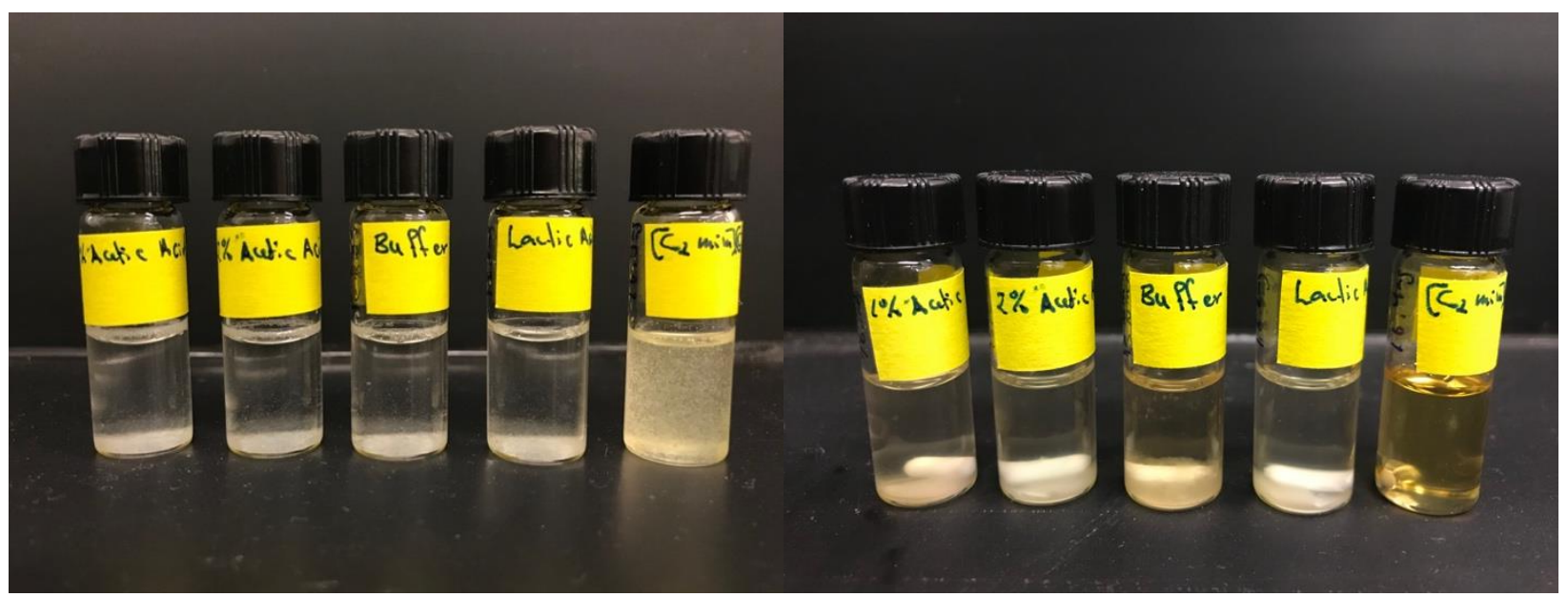

Figure S4: Pictures of aged chitosan (from left to right) in 1\% acetic acid, $2 \%$ acetic acid, buffer solution ( $0.3 \mathrm{M}$ acetic acid, $0.25 \mathrm{M}$ sodium acetate, $0.8 \mathrm{mM}$ sodium azide), $0.8 \%$ lactic acid and $\left[\mathrm{C}_{2} \mathrm{mim}\right][\mathrm{OAc}]$ pre (left) and post (right) heating $\left(80^{\circ} \mathrm{C}\right.$. Images show that the age based chitosan only dissolves in $\left[\mathrm{C}_{2} \mathrm{mim}\right][\mathrm{OAc}]$.

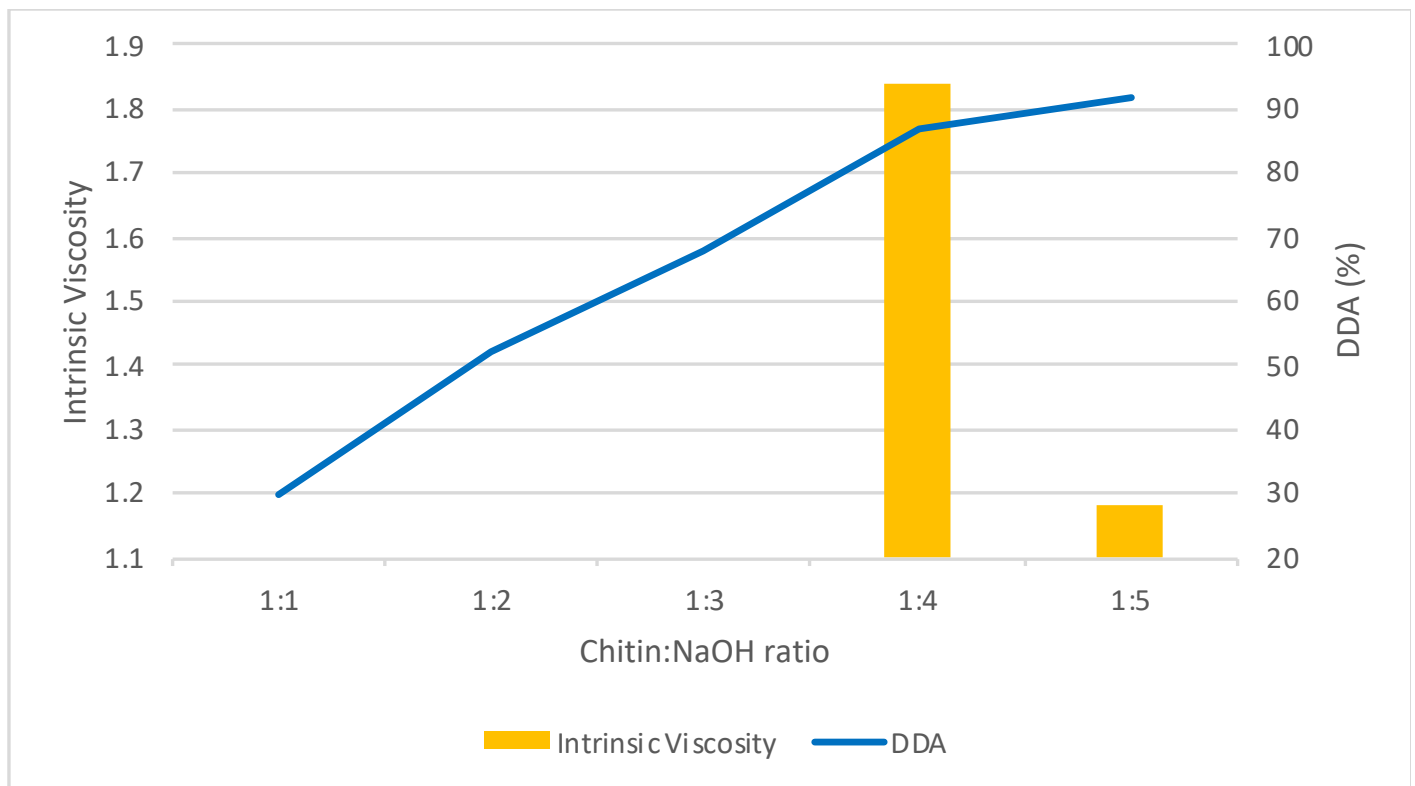

Figure S5: Effect of the chitin: $\mathrm{NaOH}$ ratio on [ $\eta$ ] and DDA in the amorphization/aging based chitin deacetylation experiments. Conditions of scheme 2 with aging at $50^{\circ} \mathrm{C}$ for 6 days. [ $\eta$ ] not measured for $1: 1,1: 2$ and $1: 3$ chitin: $\mathrm{NaOH}$ ratios.

Table S2: Initial DDA of commercial chitin, commercial chitosan and solution deacetylated chitosan acquired by ${ }^{13} \mathrm{C} C P$ MAS NMR

\begin{tabular}{|l|l|}
\hline Sample & DDA (\%) \\
\hline PG-Chitin & 4 \\
\hline Commercial Chitosan LMW & 89 \\
\hline Commercial Chitosan MMW & 96 \\
\hline
\end{tabular}




\begin{tabular}{|l|l|}
\hline Commercial Chitosan HMW & 85 \\
\hline Solution Deacetylated Chitosan & 76 \\
\hline
\end{tabular}

Table S3: Mixer-mill based commercial chitin deacetylation experiments in PTFE jar with a $\mathrm{ZrO}_{2}$ ball. DDA $=[\mathrm{H}] /([\mathrm{COMe}]+[\mathrm{H}]) \times 100$, determined by ${ }^{13} \mathrm{C}$ CP MAS NMR. LAG solvent $10 \mathrm{wt} \%$ : none, dichloromethane, acetonitrile, ethyl acetate, methanol, ethanol and deionized water.

\begin{tabular}{|l|l|l|l|}
\hline Milling time (min) & NaOH:chitin ratio & DDA (\%) & LAG solvent \\
\hline 30 & 1 & 5 & none \\
\hline 30 & 2 & 6 & none \\
\hline 30 & 3 & 6 & none \\
\hline 30 & 4 & 7 & none \\
\hline 30 & 5 & 7 & none \\
\hline 60 & 5 & 6 & none \\
\hline 90 & 5 & 7 & none \\
\hline 30 & 1 & 7 & Water \\
\hline 30 & 1 & 7 & Ethanol \\
\hline 30 & 1 & 6 & Methanol \\
\hline 30 & 1 & 6 & Dichloromethane \\
\hline 30 & 1 & 6 & Ethyl Acetate \\
\hline 30 & 1 & 4 & Acetonitrile \\
\hline 30 & 1 & 9.9 & Water $(10 \%)$ \\
\hline 30 & 1 & 14 & Water $(20 \%)$ \\
\hline 30 & 1 & 11.76 & Water (30\%) \\
\hline 30 & 1 & 11.65 & Water (50\%) \\
\hline 30 & 5 & 12.4 & Water (10\%) \\
\hline 30 & 5 & 23.8 & Water (20\%) \\
\hline 30 & 5 & 20.56 & Water (30\%) \\
\hline 30 & 5 & 19 & Water (50\%) \\
\hline
\end{tabular}

Table S4: Table of the relative humidity $(\mathrm{RH})$ study of aging of crystalline chitin for 6 days at $22^{\circ} \mathrm{C}$ with a chitin to $\mathrm{NaOH}$ ratio of 1:5.

\begin{tabular}{|l|l|}
\hline $\mathrm{RH}(\%)$ & $\mathrm{DDA}(\%)$ \\
\hline 43 & 40 \\
\hline 75 & 43 \\
\hline 98 & 60 \\
\hline
\end{tabular}

Table S5: DDA and $[\eta]$ of commercial chitin treated with or without amorphization pre-treatment (30 min milling in $\mathrm{ZrO}_{2}$ apparatus) followed by 3 to 6 days aging at 22 to $50^{\circ} \mathrm{C}$, at $98 \%$ humidity and with a chitin to $\mathrm{NaOH}$ ratio of 1:5.

\begin{tabular}{|c|l|r|r|r|}
\hline $\begin{array}{l}\text { Amorphization pre } \\
\text { treatment }\end{array}$ & $\begin{array}{l}\text { Temp. } \\
\left({ }^{\circ} \mathrm{C}\right)\end{array}$ & Aging time (days) & DDA(\%) & $\begin{array}{l}\text { Intrinsic } \\
\text { Viscosity [ } \eta\end{array}$ \\
\hline \multirow{2}{*}{ Yes } & 22 & 6 & 73 & 2.52 \\
\cline { 2 - 5 } & 30 & 6 & 90 & 1.41 \\
\cline { 2 - 5 } & 40 & 6 & 90 & 1.27 \\
\hline
\end{tabular}




\begin{tabular}{|c|c|c|c|c|}
\hline & 50 & 6 & 92 & 1.18 \\
\hline \multirow{8}{*}{ No } & \multirow{4}{*}{50} & 3 & 83 & 3.12 \\
\hline & & 4 & 84 & 3.04 \\
\hline & & 5 & 84 & 3.04 \\
\hline & & 6 & 87 & 3.01 \\
\hline & \multirow{4}{*}{22} & 3 & 50 & 3.23 \\
\hline & & 4 & 51 & 3.22 \\
\hline & & 5 & 65 & 3.12 \\
\hline & & 6 & 60 & 3.19 \\
\hline \multirow{8}{*}{ yes } & \multirow{4}{*}{50} & 3 & 95 & 1.27 \\
\hline & & 4 & 93 & 1.26 \\
\hline & & 5 & 94 & 1.22 \\
\hline & & 6 & 92 & 1.18 \\
\hline & \multirow{4}{*}{22} & 3 & 53 & 2.64 \\
\hline & & 4 & 76 & 2.76 \\
\hline & & 5 & 69 & 2.69 \\
\hline & & 6 & 73 & 2.52 \\
\hline
\end{tabular}

Table S6: DDA and $[\eta]$ of commercial chitin treated with amorphization pre-treatment (30 min milling in $\mathrm{ZrO}_{2}$ apparatus) followed by 6 days aging at $50^{\circ} \mathrm{C}$, at $98 \%$ humidity and with a chitin to $\mathrm{NaOH}$ ratio ranging from 1:1 to 1:5.

\begin{tabular}{|c|r|r|}
\hline Chitin: $\mathrm{NaOH}$ ratio & DDA(\%) & Intrinsic Viscosity $[\eta]$ \\
\hline $1: 1$ & 30 & Not measured \\
\hline $1: 2$ & 52 & Not measured \\
\hline $1: 3$ & 68 & Not measured \\
\hline $1: 4$ & 87 & 1.84 \\
\hline $1: 5$ & 92 & 1.18 \\
\hline
\end{tabular}

Table S7: Energy consumption comparison of solvo-thermal and aging methods for deacetylation of $1 \mathrm{Kg}$ of chitin into chitosan. Solvothermal was calculated for heating $1 \mathrm{Kg}$ of chitin, $18.5 \mathrm{Kg}$ of water, and $18.5 \mathrm{Kg}$ of $\mathrm{NaOH}$ to $133^{\circ} \mathrm{C}$. Aging was calculated for heating $1 \mathrm{Kg}$ of chitin, $2 \mathrm{Kg}$ of water, and $0.9 \mathrm{Kg}$ of $\mathrm{NaOH}$. Amorphization includes 30 mins of milling in $\mathrm{ZrO}_{2}$ jar with $\mathrm{ZrO}_{2}$ ball. Mixing requires 5 mins milling in PTFE jar with one $\mathrm{ZrO}_{2}$ ball.

\begin{tabular}{|l|l|l|l|l|}
\hline Method & Solvo-thermal & Amorphization & Mixing & Aging \\
\hline Energy $(\mathrm{KJ} / \mathrm{Kg})$ & 11,467 & 3,330 & 555 & 269 \\
\hline
\end{tabular}


190121-Supplementary information paper-submission TD... (2.39 MiB) view on ChemRxiv • download file 